\title{
Review Article \\ ROS Pleiotropy in Melanoma and Local Therapy with Physical Modalities
}

\author{
Sanjeev Kumar Sagwal (D) and Sander Bekeschus \\ ZIK Plasmatis, Leibniz Institute for Plasma Science and Technology (INP), Felix-Hausdorff-Str. 2, 17489 Greifswald, Germany
}

Correspondence should be addressed to Sander Bekeschus; sander.bekeschus@inp-greifswald.de

Received 21 July 2021; Revised 6 September 2021; Accepted 11 October 2021; Published 3 November 2021

Academic Editor: Bin Duan

Copyright (C) 2021 Sanjeev Kumar Sagwal and Sander Bekeschus. This is an open access article distributed under the Creative Commons Attribution License, which permits unrestricted use, distribution, and reproduction in any medium, provided the original work is properly cited.

\begin{abstract}
Metabolic energy production naturally generates unwanted products such as reactive oxygen species (ROS), causing oxidative damage. Oxidative damage has been linked to several pathologies, including diabetes, premature aging, neurodegenerative diseases, and cancer. ROS were therefore originally anticipated as an imperative evil, a product of an imperfect system. More recently, however, the role of ROS in signaling and tumor treatment is increasingly acknowledged. This review addresses the main types, sources, and pathways of ROS in melanoma by linking their pleiotropic roles in antioxidant and oxidant regulation, hypoxia, metabolism, and cell death. In addition, the implications of ROS in various physical therapy modalities targeting melanoma, such as radiotherapy, electrochemotherapy, hyperthermia, photodynamic therapy, and medical gas plasma, are also discussed. By including ROS in the main picture of melanoma skin cancer and as an integral part of cancer therapies, a greater understanding of melanoma cell biology is presented, which ultimately may elucidate additional clues on targeting therapy resistance of this most deadly form of skin cancer.
\end{abstract}

\section{Introduction}

Reactive oxygen species (ROS) are a consequence of imperfect aerobic metabolism. ROS are formed as a byproduct of electron transfer reactions from enzymatic and nonenzymatic sources [1]. This review also uses the term ROS to cover reactive nitrogen species (RNS) as many contain (reactive) oxygen. Oxidative stress is caused by the increased ROS or decrease in the activity of antioxidant systems in the cell. Slightly or detrimentally higher ROS levels have been coined oxidative eustress and oxidative distress, respectively [2]. The former relates to lower concentrations of ROS that amplify physiological processes such as proliferation and wound healing [3]. The latter covers exceedingly high levels of oxidative stress-provoking damage and cell death. Oxidative stress has been involved in several pathophysiological conditions, including cancer, by damaging lipids, proteins, and DNA [4-8]. ROS interaction with proteins impacts several signaling pathways by oxidizing redox-reactive cysteine and tyrosine residues within or nearby active sites $[9,10]$. The effects of ROS vary from reversible to irreversible depending on the ROS levels and antioxidant machinery efficiency in the cells. Milder effects of protein modifications are reversible and promote cellular signaling through a change in protein activity [7]. For example, while irreversible modification of cysteine residues in proteins can lead to permanent loss of protein function, reversible modification can be protective from excessive ROS [5]. Adaption to ROS elevation through protein modifications plays a prominent role in ROS metabolism either by activating antioxidant pathways (e.g., Kelch-like ECH-associated protein 1 (KEAP1)) through cysteine residue modification or metabolic pathways (e.g., pyruvate kinase isoenzyme type M2 (PMK2)) [9]. Other reversible modifications, including glutathionylation, S-sulfonation, CoAlation, nitrosylation, and disulfides, can modify proteins by protecting them from terminal oxidation and alter their functions to adapt to oxidative stress [5]. Subsequently, ROS-dependent signaling modulates the activation of transcription factors such as NF- $\kappa \mathrm{B}$ (nuclear factor kappa-light-chain-enhancer of activated B-cells) and AP-1 (activator protein 1) [11-13]. Numerous mechanisms through which melanoma cells limit ROS exposure have 
been described. For instance, NRF2 (nuclear factor erythroid 2 -related factor 2) is the most ubiquitous transcription factor that regulates genes involved in antioxidant defense [14]. Hypoxia and activation of oncogenes can induce NRF2, with evidence that this response is mandatory for melanoma development $[15,16]$. Thus, the influence of ROS on cellular process is complex and they have dual role of pro- and antitumorigenic effects depending on their regulation.

Based on the work done by several groups, melanoma is a ROS-operated tumor [17]. The contribution of ROS to melanoma therapy is multifaceted. In melanoma prevention studies, antioxidants failed to show any beneficial effects. In some instances, an increase in cancer development was even observed under antioxidant supplementation [18, 19]. Many studies have shown that increased oxidative stress results in increased sensitivity of cells to therapy-induced cell death [20]. Survival of cells under the burden of oxidative stress depends on activating ROS scavenging pathways that are not needed in normal cells, deducing that interference with these antioxidant pathways or additional ROS burden may selectively kill melanoma cells $[20,21]$. Impressively, several commonly used chemotherapeutic agents and physical modalities effectively induce ROS as part of their mechanism of action [21-23]. Conversely, ROS may also affect the outcome of immunotherapy [24]. For instance, chimeric antigen receptor (CAR) $\mathrm{T}$ cells are prone to hostile inflammatory conditions [25]. Hence, appropriate combinatorial approaches are essential to overcome therapy resistance and achieve better efficacy in melanoma therapy. This review discusses the origin and types of ROS. Further, their signaling and damaging effects in melanoma initiation and progression are described. Moreover, several physical treatment modalities are summarized that contribute to local ROS production and subsequent antimelanoma efficacy

\section{ROS: Types, Sources, and Regulation}

ROS are molecules and free radicals involved in the transfer of electrons from reactive oxygen. There are various tools for indirectly measuring ROS in cells and tissues while measuring ROS directly is still deficient. A selection of ROS is described hereafter, which are relevant in both physiology and pathology, including cancer.

2.1. ROS Types. The primary production site of superoxide is mitochondria (Figure 1). During the leakage of electrons at several respiratory chain respiratory complexes, especially complex I and III, molecular oxygen is reduced by one electron to produce superoxide anion $\left(\mathrm{O}_{2}{ }^{-}\right) \cdot \mathrm{O}_{2}{ }^{-}$is a moderately reactive short-lived species that dismutates spontaneously or by superoxide dismutases (SOD) (Figure 2) to $\mathrm{H}_{2} \mathrm{O}_{2}$ [26]. This type of ROS is generated by the autoxidation of various small molecules such as dopamine, flavins, and hydroquinones (Figure 3). It is produced nonenzymatically when prosthetic groups or reduced coenzymes directly transfer a single electron to oxygen. Enzymatically, NADPH oxidases (NOXs) reside on the cell membrane of many cell types to produce extracellular superoxide [27]. Superoxide releases iron by targeting iron-sulfur (Fe-S) clusters or react with nitric oxide (NO) to form peroxynitrite $\left(\mathrm{ONOO}^{-}\right)$[26]. $\mathrm{ONOO}^{-}$is a strong oxidant that indiscriminately reacts with DNA to generate double-stand breaks, oxidation of amino acids in proteins and induces lipid peroxidation by reacting with lipids.

Hydrogen peroxide $\left(\mathrm{H}_{2} \mathrm{O}_{2}\right)$ plays a role as a second messenger in several pathways [28] by oxidizing the thiol group $(-\mathrm{SH})$ on cysteine residues, resulting in the transduction of extracellular and intracellular signals and control of the gene expression [29]. Cysteine residues exist as thiolate anion (Cys-S-) at physiological $\mathrm{pH}$ and are more susceptible to oxidation compared with the protonated cysteine thiol (Cys-SH) [9]. Reversible modifications like sulfenic species are generated after enzyme-mediated oxidation of cysteine residues by $\mathrm{H}_{2} \mathrm{O}_{2}$ and can be returned to reduced states by the action of thioredoxin (TRX) and glutaredoxin reductases (GRX) [30]. However, advanced oxidation to sulfinic acid and irreversible oxidation to sulfonic acid results in permanent damage of protein function [30]. Cells have professional enzymes directed to prevent the buildup of intracellular $\mathrm{H}_{2} \mathrm{O}_{2}$, primarily peroxiredoxins (PRDXs) and glutathione peroxidases (GPXs) [30]. To decrease $\mathrm{O}_{2}{ }^{-}$-mediated $\mathrm{ONOO}^{-}$formation (Figure 2), SOD1 (located in the cytoplasm and mitochondria) and SOD2 (located in the mitochondrial matrix) convert $\mathrm{O}_{2}{ }^{-}$generated by mitochondria and NOXs into $\mathrm{H}_{2} \mathrm{O}_{2}$ [30]. $\mathrm{H}_{2} \mathrm{O}_{2}$ diffuses freely to other sites in or outside the cell. When present in peroxisomes, catalase (CAT) can react with $\mathrm{H}_{2} \mathrm{O}_{2}$ to form water and oxygen. The endoplasmic reticulum is another primary source of $\mathrm{H}_{2} \mathrm{O}_{2}$ that is generated by the combined action of protein disulfide isomerase (PDI) and ER oxidoreductin 1 (Ero 1) during the formation of disulfide bonds [31]. It is noticeable that the concentration of $\mathrm{H}_{2} \mathrm{O}_{2}$ defines its role as a signaling molecule (1-10 $\mathrm{nM})$ regulating kinases and phosphatasedriven pathways or causes oxidative stress (>100 nM) [28].

Hydroxyl radicals ( $\mathrm{OH} \cdot)$ are the most reactive type of ROS. It is generated in the Fenton reaction with $\mathrm{H}_{2} \mathrm{O}_{2}$ [32], instigating lipid peroxidation and commencing lipid radicals and lipid peroxyl radicals [33]. These short-lived radicals initiate lipid peroxidation by reacting with hydrogen atoms of polyunsaturated fatty acids, which are highly reactive because of the double bonds between carbon atoms in those fatty acids. Lipid peroxidation and GPX4 regulate an iron-dependent cell death known as ferroptosis, relevant to normal and pathological processes [34]. Several other transition metal ions can also react with $\mathrm{H}_{2} \mathrm{O}_{2}$ to produce peroxyl and alkoxyl radicals [32]. The reduction of $\mathrm{Fe}^{3+}$ to $\mathrm{Fe}^{2+}$ by superoxide ion also leads to $\mathrm{OH}^{-}$under specific conditions [35].

2.2. ROS Sources. There exist several sites inside a cell that generates ROS. A large share of intracellular ROS is produced in the electron transport chain (ETC) [9]. ROS generated by the ETC into the mitochondria can be delivered into the cytoplasm through the permeability transition pore (PTP) [29]. The opening of PTP leads to a decrease in the concentrations of ATP and $\mathrm{Ca}^{2+}$ to release cytochrome $\mathrm{c}$ [36-38]. This fuels the collapse of the membrane potential 


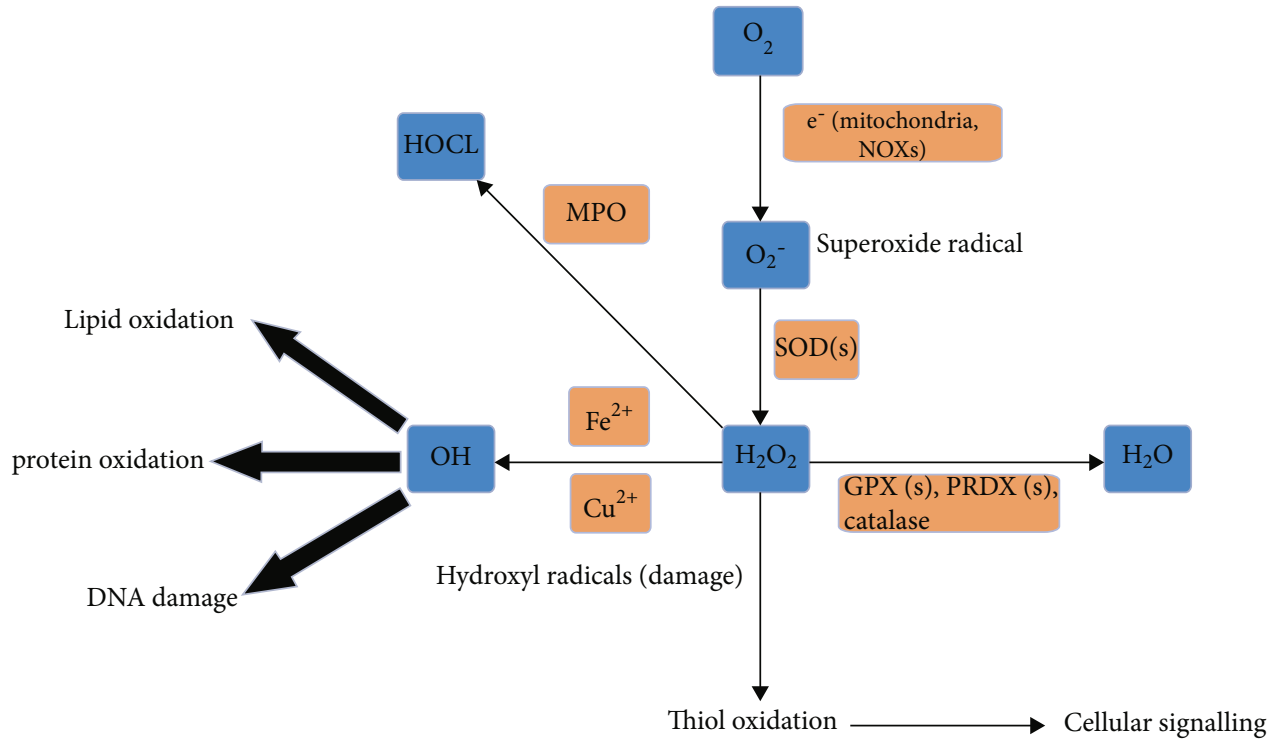

FIgURE 1: ROS types and generation. $\mathrm{H}_{2} \mathrm{O}_{2}$ and $\mathrm{O}_{2}{ }^{-}$are released by mitochondria into the cytosol. SODs convert $\mathrm{O}_{2}{ }^{-}$in the cytosol to $\mathrm{H}_{2} \mathrm{O}_{2}$. NADPH oxidases (NOXs) also generate $\mathrm{O}_{2}{ }^{-}$in the cytosol. $\mathrm{H}_{2} \mathrm{O}_{2}$ is converted to $\mathrm{H}_{2} \mathrm{O}$ by GPXs and PRDXs. The reaction of ferrous or cuprous ions with $\mathrm{H}_{2} \mathrm{O}_{2}$ forms $\mathrm{OH}$. radicals, subsequently damaging lipids, proteins, and DNA. $\mathrm{H}_{2} \mathrm{O}_{2}$ affects signaling through oxidations of protein thiols. Abbreviations: GPXs: glutathione peroxidases; PRDXs: peroxiredoxins; SODs: superoxide dismutases. Created with http://biorender.com.

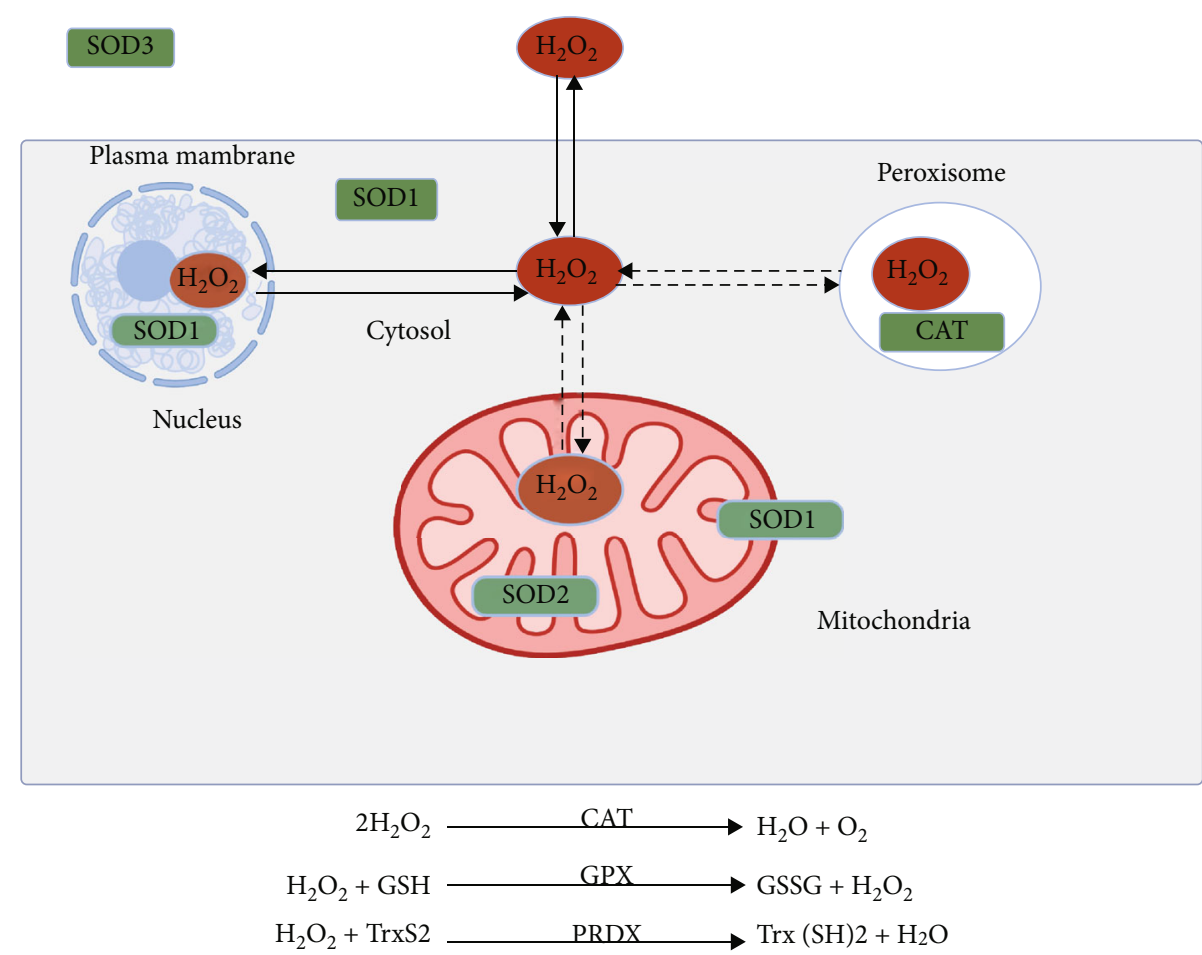

FIGURE 2: ROS detoxification. The cell is equipped with defense mechanisms to scavenge ROS. Detoxification enzymes like CAT react with $\mathrm{H}_{2} \mathrm{O}_{2}$ to catalyze the formation of $\mathrm{H}_{2} \mathrm{O}$ and $\mathrm{O}_{2}$. GPX and PRDX reduce $\mathrm{H}_{2} \mathrm{O}_{2}$. Abbreviations: CAT: catalase; GPX: glutathione peroxide; PRDX: peroxiredoxins; GSSG: glutathione disulfide, oxidized; GSH: glutathione, reduced. Created with http://biorender.com.

of mitochondria and a sudden increase in ROS generation by ETC [39]. It has been affirmed that this results in autophagy and apoptosis or necrosis, depending upon the extent of organelle damage. Hence, mitochondria are a major site for
ROS production, especially complexes I and III [40, 41]. In addition to mitochondria, peroxisomes and the endoplasmic reticulum produce ROS. Peroxisomes contain several $\mathrm{H}_{2} \mathrm{O}_{2}$ generating enzymes, and catalase (CAT) in this organelle 


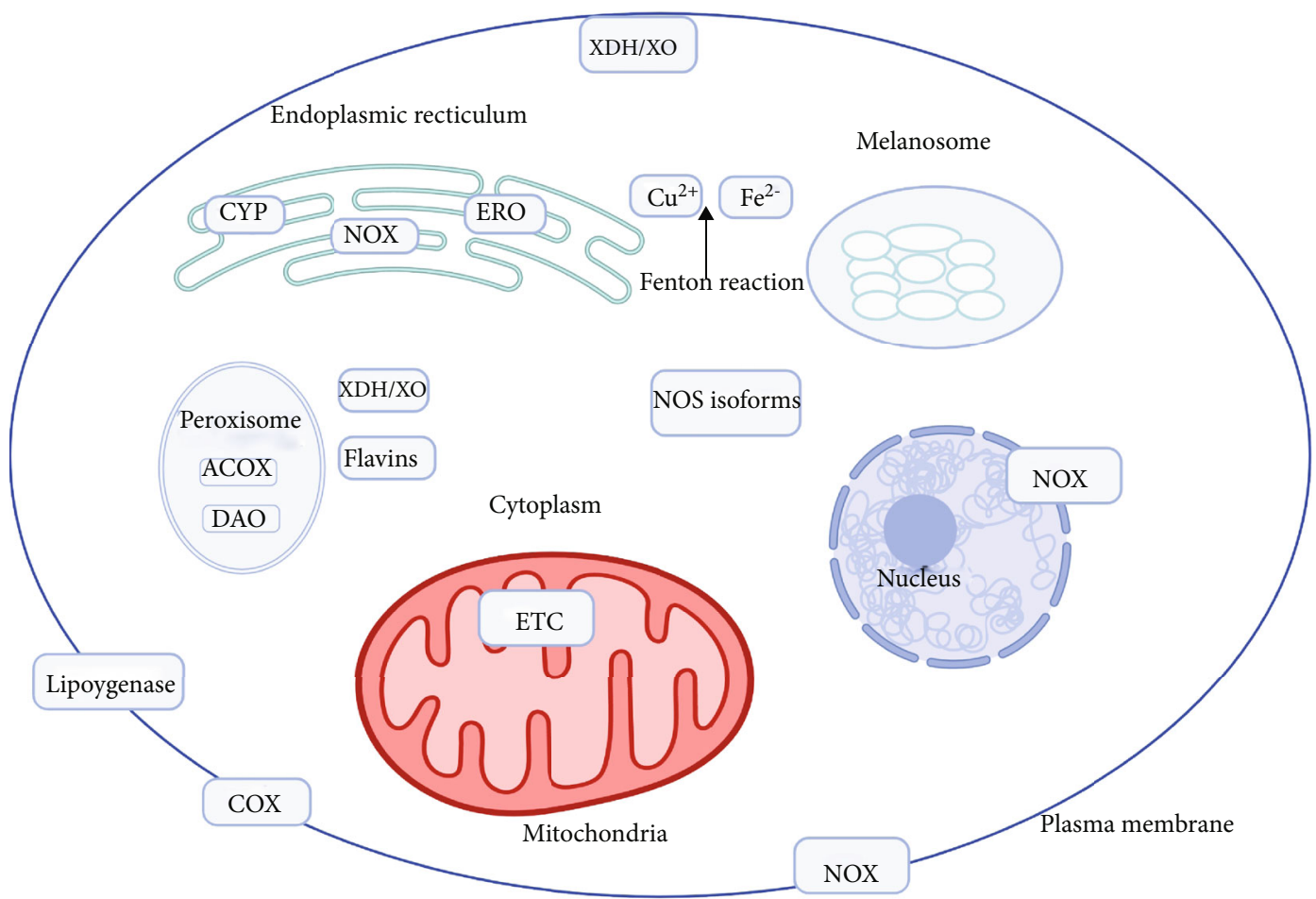

FIGURE 3: Sources of cellular ROS production. Prominently, melanosomes, mitochondria, and NOXs and NOS uncoupling generate ROS. Primarily, NOXs are localized in the plasma membrane, although they can be found on other membranes as well, including the endoplasmic reticulum and mitochondria. Cytosolic enzymes such as $\mathrm{XO}, \mathrm{XDH}$, and soluble components like flavin contribute to intracellular ROS production. Oxidative protein folding by ERO1 and enzymes like CYP in the endoplasmic reticulum and lipoxygenase and cyclooxygenase in the plasma membrane also generate intracellular ROS. Peroxisomes containing DAO and ACOX generate ROS, too. Abbreviations: $\mathrm{XO}$ : xanthine oxidase; $\mathrm{XDH}$ : xanthine dehydrogenase; ERO1: endoplasmic reticulum oxidoreductin; CYP: cytochrome P450-dependent monooxygenases; DAO: D-amino oxidase; ACOX: acyl-CoA oxidase. Created with http://biorender.com.

detoxifies several substrates and toxic molecules (Figure 2). Other ROS-generating enzymes include xanthine oxidase, $\alpha$-ketoglutarate dehydrogenase complex, and NOXs [42]. Apart from phagocytes, NOXs are also found in nonphagocytic cells that regulate cellular growth responses [42]. It has been noticed that ROS produced by NOXs enhances melanoma cell proliferation through activation of NF- $\kappa \mathrm{B}$ [43]. The oxidase components are expressed by both melanoma cells and melanocytes [43]. In primary and metastatic melanoma cells, higher levels of NOX and oxidative have been found compared to normal human melanocytes [44]. $\mathrm{ONOO}^{-}$, a species generated by the interaction of NO- with NOX-generated $\mathrm{O}_{2}^{-}$, is highly reactive toward redoxsensitive amino acid residues, including cysteine and tyrosine [42]. Enzymes like NO. synthases (NOS), xanthine oxidoreductase, and cytochrome c oxidase can be involved in NO. production [45].

2.3. ROS Regulation. To prevent ROS overload in the cytosol and ER, cells have antioxidant defense mechanisms in place tightly regulating ROS levels and maintaining the reduced state of critical biomolecules (Figure 4). Reduced glutathione (GSH) is the prolific reducing agent in the cytosol and ER, though the ratio of reduced to oxidized (GSSG) glutathione (GSH: GSSG) varies in these two compartments [46]. GSH diffuses from the production site to distant sites by passing through the membranes and plays a prominent role in the ROS detoxification in cancer cells [47]. GSH is a glutamate, glycine, and cysteine tripeptide, synthesized by two enzymatic steps catalyzed by glutamate-cysteine ligase (GCLC) and GSH synthetase (GSS) to from the tripeptide. GSH is used by GSH peroxidases (GPXs) and GSH S-transferases (GSTs) for the elimination of ROS [48]. In addition to GSH-dependent antioxidant systems, there is another less abundant small protein antioxidant system consisting of PRDXs, having a high catalytic activity toward $\mathrm{H}_{2} \mathrm{O}_{2}$ and being rejuvenated by thioredoxin (TXN) and sulfaredoxin (SRX) networks [49]. The oxidized forms of TXN and GSH are rejuvenated by TNX reductases [50] and GSH reductases (GR), respectively, using NADPH as an electron donor [51]. Oxidative stress develops when the production of ROS outpaces the scavenging ability of the cellular defense system made up of redox enzymes and several other antioxidant molecules [52]. Oxidative stress promotes the expression of enzymes involved in TXN and GSH systems, implying that they work in accord to buffer the stress induced by ROS molecules [53]. TXN is less significant as an antioxidant due to its lower concentration in cells $(\mu \mathrm{M}$ compared to $\mathrm{mM}$ range of GSH), controlling the redox state of specific factors by performing rapid oxidation-reduction reactions kinases and transcription factors [53]. In addition, GSH can reverse modifications such as sulfenylation 


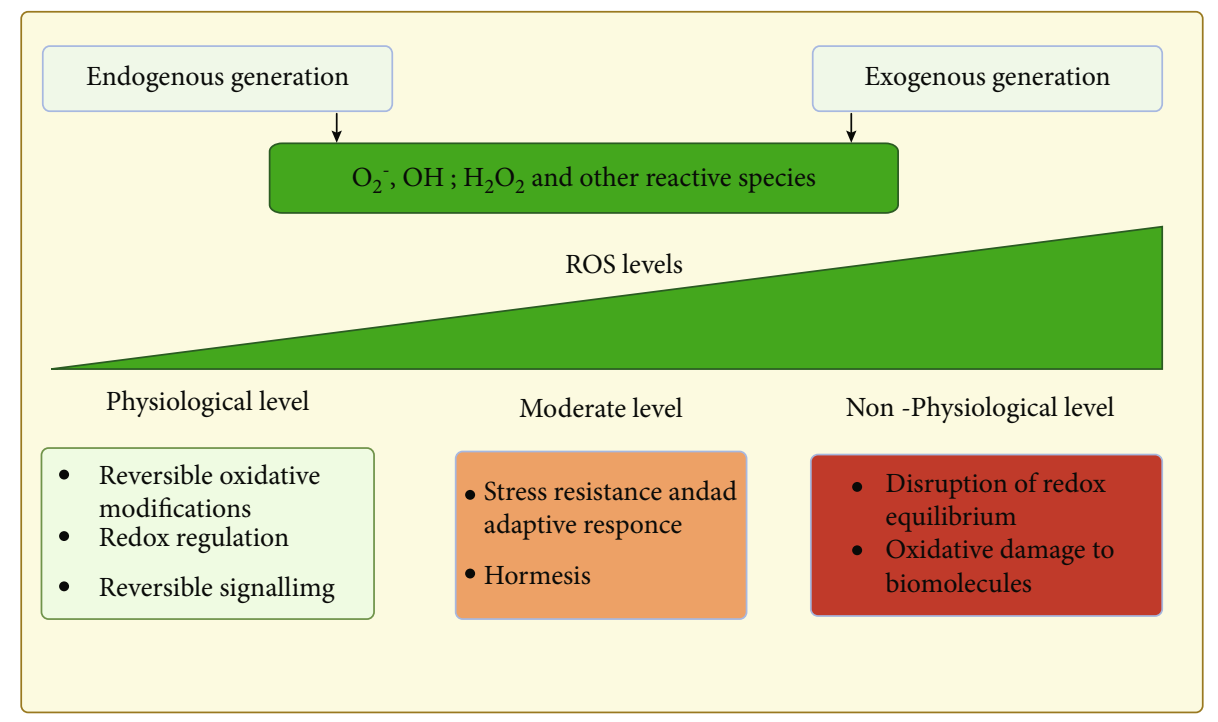

FIGURE 4: Cellular responses to endogenous and exogenous ROS. The response gradient will vary with the cell type, the location of ROS source inside the cells, and the activity of detoxifying enzymes. Blue and red colors represent predominantly beneficial or deleterious responses to ROS levels. Created with http://biorender.com.

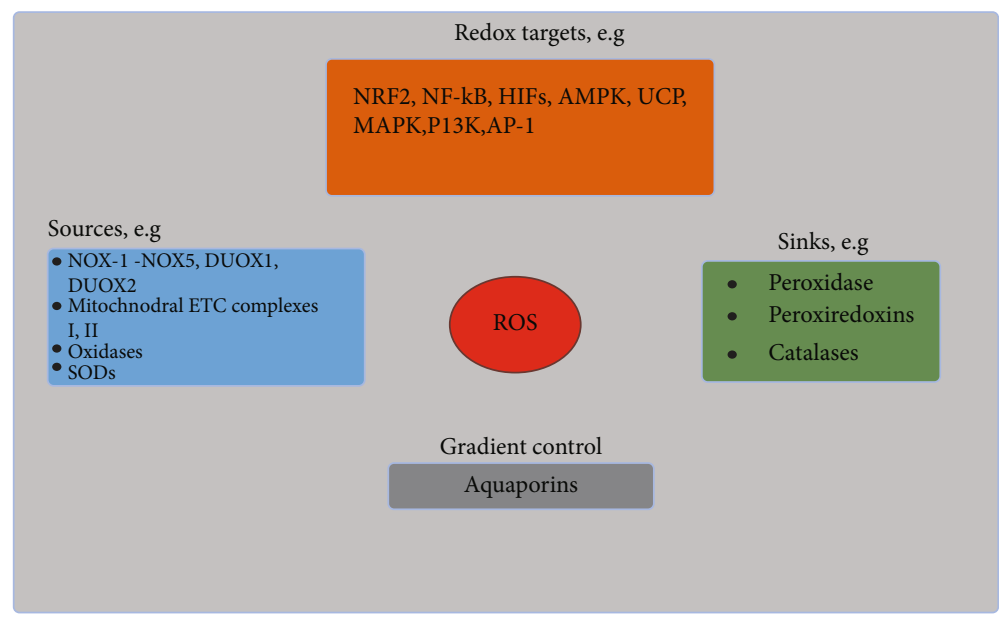

FIGURE 5: Targets and modulators of ROS. Sources of ROS (blue), its targets (orange), aquaporins (grey), and sinks (purple) are shown. Redox targets serve as the center point to support biological functions. SODs serve as a source for ROS and as a sink for the $\mathrm{O}_{2}{ }^{-}$. Under homeostatic conditions, moderate or low levels of ROS induce the activation and inactivation of transcriptions factors. These transcription factors regulate stress adaptation (including antioxidant response), inflammatory response, hypoxic response, metabolic adaptation, and cell death. Abbreviations: SODs: superoxide dismutases.

mediated by ROS. In summary, several ROS sources affect redox targets and are additionally controlled by ROS sinks, while melanoma cells showed altered expression among all those steps (Figure 5).

\section{Pleiotropic Roles of ROS in Melanoma Biology}

Melanocytes are sensitive to oxidative stress induced by an imbalance of ROS. In normal melanocytes, melanin acts as an antioxidant and suppresses $\mathrm{H}_{2} \mathrm{O}_{2}, \mathrm{O}_{2}{ }^{-}$, and singlet oxygen [54]. However, melanogenesis in melanoma cells itself is a source of ROS and oxidative stress [55]. $\mathrm{O}_{2}{ }^{-}$and diffusible $\mathrm{H}_{2} \mathrm{O}_{2}$ produced by the mitochondria and NOXs play an important role in melanocyte malignant transformation [27]. Such Oxidative stress can cause an imbalance of homeostasis in melanocytes, jeopardizing their survival or leading to malignant transformation. In melanoma, NOX4 is highly expressed as compared to the low levels in melanocytes [56]. Overexpression of NOX1, uncoupled eNOS, and NOX4 produced ROS in melanoma, linked to the epithelial-mesenchymal transition [56, 57]. Uncoupled eNOS contributes to superoxide production during malignant transformation [57]. NOS-dependent superoxide formation has a prominent role in melanoma genesis [57]. Furthermore, these data show that superoxide production by eNOS plays a prominent role in melanoma cells' survival and melanocyte malignant transformation. In addition to 
that, melanoma cells require NADPH generating enzymes to promote distant metastasis. $\mathrm{H}_{2} \mathrm{O}_{2}, \mathrm{O}_{2}{ }^{-}$, and singlet oxygen are involved in various stages of melanomagenesis and tumor microenvironment (TME) quality, including hypoxia, metabolic profiles, immune responses, biosynthesis of melanin, metastasis, and oxidative profiles. ROS increases the toxicity of RNS dramatically begins melanomagenesis that attributes to the leakage of melanosome contents. Several findings suggested that worsen oxidative stress leads to the mutation in several melanoma-associated genes. For example, the somatic BRAF V600E mutation in melanoma can be induced by oxidative stress [58] and loss of p16 results in elevated ROS and mitochondrial biogenesis of human melanocytes [59]. In addition, melanoma progression is associated with depletion of PTEN and the resulting increase in $\mathrm{O}_{2}{ }^{-}$[60]. Hence, oxidative stress is a driver of melanomagenesis.

3.1. Antioxidant Network. The role of antioxidant systems is dual in melanoma initiation, progression, and metastasis. The misbalanced activation of the antioxidant transcription factor NRF2 leads to the promotion of melanoma [61]. This transcription factor is entangled in transcribing several GSH and TXN antioxidant pathways genes under various physiological and pathophysiological conditions [62]. In basal conditions, the level of NRF2 is under control by its association with KEAP1, which promotes its degradation via the ubiquitin-proteasome pathway. Increased ROS levels lead to oxidative stress modifications of cysteine residues of KEAP1, leading to flawed NRF2 ubiquitination and NRF2 accumulation [61]. Several mechanisms exist for NRF2 accumulation, such as mutations in the KEAP1 and NRF2 genes, carcinogen-induced DNA damage, and inactivation of KEAP1 due to methylation of its promoter [63]. The role of NRF2 is convoluted and tissue dependent. Loss of NRF2 bolsters epithelial-mesenchymal transition through ROS to promote migration and invasion to support invasion and diapedesis of cancer cells $[64,65]$. In contrast, NRF2 can uphold migration and invasion through the BACH1 (BTB domain and CNC homolog 1) transcription factor [66]. Therefore, the role of ROS and NRF2 is complex at different tumor stages. Other agents involved in antioxidant defense and $\mathrm{H}_{2} \mathrm{O}_{2}$ removal include GPXs, PRDXs, and CAT [12]. The antioxidant capacity of melanoma differs from normal melanocytes and that of other skin cancers. The expression and activity of the antioxidant enzymes catalases, MnSOD2, and $\mathrm{Cu} / \mathrm{Zn}-\mathrm{SOD} 1$ are higher in melanoma than in basal cell carcinoma and squamous cell carcinoma [67]. This explains that increased oxidative stress is an important marker in melanoma development. Furthermore, the GSH: GSSG ratio is also higher in melanoma compared with the other skin tumors. This suggests that in melanoma, the increased levels of GSH can readily scavenge ROS and that the subsequently formed GSSH is efficiently reduced to GSH. Collectively, these data imply that melanoma has a better antioxidant status than other skin tumors. The increased resistance of melanoma cells to oxidative stress is not observed in melanocytes [68], suggesting that acquiring an elevated antioxidant network is critical for melanoma development. In primary melanoma, Mn-SOD2, Cu/Zn-
SOD1, and CAT expression are elevated compared with normal skin and melanocytic nevi [67]. In addition, melanoma metastases show improved resistance to oxidative stress and display high levels of ferritin expression compared with their corresponding primary melanomas [69]. Ferritin binds to and prevents iron from being reduced in the Fenton reaction, thereby averting $\mathrm{OH} \cdot-$ induced lipid peroxidation and apoptosis [69]. Summative, these findings indicate that primary and metastatic melanomas are highly resistant to oxidative stress through the increased activity of several antioxidative mechanisms. In other words, inhibition of ROS by antioxidants does not have a predictable outcome on cell function since the role of ROS changes under differing environmental conditions. For future aspects, it will be essential to identify specific molecular targets of ROS under different conditions to modulate pathways downstream of ROS that increase adaptation to stress to increase therapeutic efficacy.

3.2. Apoptosis. In response to ROS, melanoma cells can, in principal, succumb to regulated cell death. However, in approximately half of the sporadic melanomas, Protein kinase B, also known as AKT, is hyperactivated because of gene amplification and decreased PTEN (phosphatase and tensin homolog) activity [70]. Activated AKT can subsequently phosphorylate and thereby inhibit the activity of the proapoptotic factors $\mathrm{BAD}(\mathrm{Bcl}-\mathrm{xL} / \mathrm{Bcl}-2$-associated death promoter), caspase (cysteinyl-aspartate specific protease) 9, forkhead transcription factor, GSK3 (glycogen synthase kinase-3), and IKK (inhibitor of NF- $\kappa \mathrm{B}$ ). AKT stabilizes cells with extensive mitochondrial damage, which can generate surplus ROS [60]. Furthermore, AKT induces the expression of the ROS-generating enzyme NOX4 in melanoma cells and growth melanoma cells in mice [60]. In addition, the RAS/BRAF/MEK/ERK mitogen-activated protein kinase pathway is constitutively activated in melanoma via an activating mutation in BRAF or autocrine growth factor stimulation [71] and is a crucial modulator of melanoma initiation and progression [72]. Mitogen-activated protein kinases regulate ROS production by melanoma cells and cooperate with antiapoptotic proteins to maintain melanoma cell viability [73]. ROS constitutively activate NF- $\kappa \mathrm{B}$ [74], a transcription factor critically involved in cell survival [75]. The activation of NF- $\kappa \mathrm{B}$ has been proposed as an event that promotes melanoma tumor progression [76]. Transcription activation of NF- $\kappa \mathrm{B}$-regulated chemokines enhances melanoma progression through autocrine and paracrine loops, resulting in autonomous growth and invasion of melanoma cells [77]. Furthermore, ROS can activate AP-1 [78], a transcription factor critically involved in RASinduced oncogenic transformation [79]. Furthermore, ROS regulate the expression of matrix metalloproteinase (MMP)1, MMP2, and urokinase plasminogen activator (uPA) [80, 81]. These proteinases are highly expressed in melanoma [82] and contribute to their migratory capacity. Recently, ROS-induced apoptosis of melanoma cells was shown to contribute to vasculogenic mimicry [83]. This process mimics the activity of endothelial cells and results in the formation of a fluid-conducting, matrix-rich meshwork [84] 
that contributes to melanoma progression $[85,86]$. As such, the proapoptotic activity of ROS contributes to melanoma progression. ROS' proapoptotic and antiapoptotic effects in melanoma cells appear to be a driving force of melanoma development.

3.3. Hypoxia. The role of mitochondrial ROS in apoptosis and hypoxia-induced gene transcription has been elucidated recently [15]. The well-established role of mitochondrial ROS for the stabilization of hypoxia-inducible transcription factors (HIFs) under hypoxia leads to angiogenesis through the upregulation of vascular endothelial growth factor (VEGF) expression [87]. The epidermal component of normal skin in which melanocytes reside is a mildly hypoxic environment, predicted due to the distance between the skin and superficial blood vessels [88]. To counteract the adverse effects of low oxygen levels, HIFs activate gene expression regulating multiple biological processes, including metabolism, proliferation, apoptosis, and migration [89]. HIF-1 regulates most of the hypoxia-responsive genes [90]. The transcription factor consists of a constitutively expressed $\beta$ subunit and an oxygen-monitored $\alpha$-subunit. Hence, HIF-1 is the master activator for dozens of target genes transcribed by cells in response to low oxygen concentrations [91]. HIF1 activation is also required for the AKT-mediated transformation of melanocytes, hence regulating apoptosis [88].

Studies have identified increased HIF-1 expression and activity in melanoma under normoxia mediated by ROS and NF- $\kappa$ B $[92,93]$. Under normoxic conditions in nonmalignant cells, HIF-1 is rapidly degraded by the ubiquitinproteasome system, and it is upregulated in a hypoxic microenvironment [94]. However, it has been recently reported that HIF-1 can be upregulated under normoxia in response to growth factors, hormones, cytokines, UV irradiation, and metal ions [95-97]. In addition, several HIF target genes are strongly expressed in melanoma already under normoxic conditions, and elevated HIF-1 activity was found in melanoma cell lines under normoxic conditions in contrast to other types of tumors. Immunohistochemistry of malignant melanoma showed focal expression of HIF-1 in cancer tissue independent of regional hypoxia [15, 89]. Furthermore, several studies have demonstrated that part of the normoxic expression of VEGF and AngPTL4 depended on HIF-1 [98]. Interestingly, incubation of melanoma cells under reduced oxygen tension did not lead to a more substantial upregulation otherwise found in nonmelanoma cells, supporting the high basal expression of HIF-1 under normoxia $[98,99]$.

Melanocytes are more prone to oncogenic transformation when grown in a hypoxic environment. The cells' primary function is delivering melanin in melanosomes to keratinocytes resulting in protection against the harmful effects of UV radiation [88]. Within the melanocytes, the synthesis of melanin results in the generation of $\mathrm{H}_{2} \mathrm{O}_{2}$ and, if inappropriately processed, $\mathrm{OH}$. and other ROS [73]. In particular, melanosomes within melanoma cells are characteristically abnormal, with fragmented melanin and disrupted membranes. The disruption of melanosomal melanin is an early event in the etiology and progression of melanoma, leading to increased oxidative stress, ROS production, and DNA mutation [4, 6, 83]. Several studies revealed that such ROS are responsible for the increased HIF activity under normoxia in melanoma. The activity and protein level of HIF are strictly controlled by the quenching of ROS or inducing reagents. The crucial redoxsensitive transcription factors in mammalian cells are NF$\kappa \mathrm{B}, \mathrm{NRF} 2$, and AP-1 $[74,76]$. ROS can activate the transcription factor NF- $\kappa \mathrm{B}$ that is constitutively activated in melanoma cells $[74,76]$. NF- $\kappa \mathrm{B}$, in turn, can induce HIF-1 expression and NF- $\kappa \mathrm{B}-\mathrm{HIF}-1$ interaction contributes to breast cancer metastatic capacity $[88,100]$. Studies confirmed the regulation of NF- $\kappa \mathrm{B}$ through ROS in malignant melanoma and showed that the inhibition of NF- $\kappa$ B by the adenoviral overexpression of the IKK led to the attenuation of the HIF activity [101]. These data support the concept of transcriptional regulation of HIF-1 by NF- $\kappa \mathrm{B}$ under normoxic conditions.

Besides the described ROS-dependent regulation, HIF-1 is translationally regulated by the mammalian target of rapamycin (mTOR). The mechanism of regulation of HIF by mTOR is poorly understood. It appears that under hypoxia, mTOR is inactivated, which led to the conclusion that mTOR signaling to HIF is oxygen independently regulated [102]. Under severe hypoxia, no influence of mTOR inhibitors was observed; thus, the stimulation of HIF-1 by mTOR is relevant under mild hypoxia or even normoxia only [102]. Several studies confirmed this hypothesis, as rapamycin reduced the HIF activity and protein expression under normoxia. One study showed that rapamycin, in contrast to ROS and NF- $\kappa$ B, does not influence HIF-1 mRNA expression, suggesting posttranscriptional regulation. Recently, Aprelikova and colleagues described a novel role for the cancer-testis antigen melanoma antigen-11 (MAGE11) as an inhibitor of prolyl hydroxylase (PHD2) in hypoxic responses [103]. Strong expression of MAGE-11 has been seen in different melanoma cell lines, which led to HIF stabilization under normoxia [104]. The finding that the regulation of protein abundance and the transcriptional regulatory network is crucial in controlling HIF-1 levels in melanoma and other tumor types opens new therapeutic options in modulating HIF-1 activity.

3.4. Melanin Biosynthesis. Exposure to UV is suggested to be a significant risk factor for developing melanoma, especially during childhood $[105,106]$. However, this only refers to the sun-induced type of melanoma and not other types of melanoma that were never exposed to the sun [107]. About $90 \%$ 95\% of the solar UV radiation that reaches the earth is UVA. Due to its high penetration capacity, UVA can irradiate melanocytes even through clothes and windows [106]. In response to the direct mutagenic effect of UV radiation, melanin synthesis by melanocytes is induced. Although melanin is initially necessary for protection from UV, it can turn into a prooxidant under oxidative stress because of inflammation, UV exposure, or higher metabolic processes, thus regulating epidermal homeostasis and affecting melanoma behavior [108]. UV-induced melanin biosynthesis results in an increased cellular concentration of its reactive 
precursors. The initial reaction in melanin formation is the enzymatic oxidation of L-tyrosine to dopaquinone [109]. This reactive precursor is either converted into monomers that polymerize into black/brown eumelanin or reacts with a -SH group of cysteine to form 5-S-cysteinyldopa, ultimately forming the basic monomers for red/light brown phaeomelanin. Cysteine is a necessary amino acid for phaeomelanin production, even though it is also a part of the GSH molecule, which acts as a part of the defense system against intracellular ROS [110]. When cysteine is used for increased UV-induced production of phaeomelanin, less GSH is produced, and oxidative stress may be more likely. Oxidative stress, in turn, releases iron from its intracellular storages into the cytosol of mammalian cells [111]. In the presence of large amounts of iron, which is frequently observed in melanoma and its precursor stages but not in normal melanocytes [110], phaeomelanin and 5-S-cysteinyldopa become prooxidants [110]. Oxidized melanin reacts with $\mathrm{O}_{2}$ to form $\mathrm{H}_{2} \mathrm{O}_{2}, \mathrm{O}_{2}{ }^{-}$, and other radicals [104] and adversely affects ROS homeostasis. During the biosynthesis of phaeomelanin, 5-S-cysteinyldopa can disturb redox homeostasis directly through its ROS production in the presence of iron and indirectly through depletion of the GSH antioxidant buffer system. Their independent actions or dependent interaction play a role in UV-dependent or -independent melanomagenesis and progression and in drug resistance, as melanocytes and melanoma have higher ROS levels that seem to coevolve with enhanced antioxidant defense systems [112]. Thus, melanin and melanogenesis play a dual role in melanoma. They protect the melanocytes against insults, such as oxidative stress and UV radiation, but accelerate melanoma progression and weaken the effects of chemotherapy and radiation therapy $[109,113]$.

3.5. Metabolic Profile. Tumor cells are metabolically hyperactive, so it requires high ATP levels to enable cell proliferation. In melanoma, ATP is predominantly generated through aerobic glycolytic metabolic pathways and lactic acid production, which leads to several advantages for melanoma cells [114]. This includes, for instance, higher proliferation of tumor stem cell populations, increased hypoxia, elevated M2 macrophage polarization, lower intratumoral $\mathrm{T}$ cell activation, additional NADPH for ROS detoxification, and metastasis via MMP production. An in-depth analysis of adaptive redox homeostasis in melanoma and energy metabolism has been provided recently $[115,116]$, and the reader is referred to these and complementing views on oxidative phosphorylation [117].

3.6. Metastasis. Over the recent years, it has become evident that early inflammatory and angiogenic response and remodeling of the extracellular proteins are key factors (i.e., type I collagen) in creating a microenvironment that sustains tumor growth and metastasis [118]. Metastasis is a hallmark of most malignant tumors and the primary cause of mortality and morbidity in patients with melanoma [119]. The entry of tumor cells into the circulation is the critical rate-limiting step in metastasis that requires MMP expression [119], uroplasminogen activation, epidermal growth factor receptor-driven polarity changes and migration, interaction with integrins [120], and other mechanisms all tightly linked to ROS. The cytoplasmic TRX is a ubiquitous thiol-reducing system implicated in cancer progression of melanoma [121]. TRX can be bound by the endogenous inhibitor thioredoxin-interacting protein (TXNIP), which negatively regulates TRX [121]. Importantly, inhibition of TRX activity promotes the transendothelial migration (TEM) of melanoma cells in vitro through endothelial injury and the loss of VE-cadherin-mediated endothelial cell-cell adhesion [122]. Overexpression of TRX inhibits both the baseline and ROS-induced TEM. Therefore, ROS enhance the TEM of melanoma cells during intravasation, and XNIP and inhibition of TRX activity could trigger this mechanism. It has also been observed that hypoxia in melanoma xenografts induces a higher metastatic frequency by increasing the expression of hypoxia-inducible genes promoting metastasis in a radiated transplant animal melanoma model [122]. However, the regulation of intravasation in vivo is not simply a matter of high or low intracellular concentrations of ROS. It requires the coordinate expression and activity of, for example, IL-8-mediated chemotaxis and CD9 and the integrin-mediated adhesion of melanoma cells to vascular endothelial cells [122]. The expression of the genes that promote melanoma metastasis is upregulated after subcurative melanoma irradiation [122]. Intriguingly, antioxidant supplementation in vivo was observed to spur rather than inhibit melanoma metastasis in mice inoculated with melanoma cells individually isolated from patients [123]. The authors found that blood and viscera are especially impinging strong oxidative stress in melanoma cells, forming a natural barrier against cancer metastasis. Antioxidants hampered this barrier and thus allow melanoma cells that had migrated to the circulation to survive better, subsequently forming more metastasis. These results were reiterated in a parallel in vivo study using the antioxidant $\mathrm{N}$ acetyl-cysteine (NAC) [124].

3.7. ROS and Different Cell Types in the Tumor Microenvironment. The production of ROS by tumor cells plays a prominent role in driving tumorigenesis by shaping the tumor microenvironment (TME) $[125,126]$. In addition, ROS generated by nontumor cells infiltrating the TME collectively decide the overall oxidative state of local TME. The TME consists of cancer cells, stromal cells, and immune cells. Immune cells infiltrate the environment of cutaneous melanoma during its early onset and throughout tumor development [127]. During inflammation, the migration of myeloid cells such as neutrophils, monocytes, eosinophils, and tissue-resident macrophages, dendritic cells, and mast cells play a role in cancer development [128].

Macrophages are of central importance in melanoma initiation and progression, especially tumor-associated macrophages (TAM) [129]. These cells fuel tumor growth by creating an immunosuppressive micro milieu via the production of chemokines, cytokines, and other mediators. Intriguingly, TAM polarization in the TME is associated with ROS and oxidative stress [130]. TAM, in turn, autoamplify ROS production via aberrant activation of NOX and 
NOS. The released species react to form $\mathrm{ONOO}^{-}$, a mutagenic agent that inhibits $\mathrm{T}$ cell activity [131]. This will affect cells nearby, their integrity, and the composition of the TME, such as matrix remodeling and angiogenesis [132]. In addition, this exerts selective pressure on the development of genetically adapted tumor cells with high resistance to oxidative stress pressure, affecting melanoma therapy [128]. It is also well established that ROS leads to metabolic reprogramming of different cell types in the TME $[133,134]$.

ROS-mediated metabolic reprogramming also changes the energy requirements of T cells in the TME $[135,136]$. Effector $\mathrm{T}$ cells $\left(\mathrm{T}_{\mathrm{eff}}\right)$ are less oxidative and have more metabolic activity than naive $T$ cells $\left(T_{n}\right)$. Naive $T$ cells keep in check the ROS levels by persistently synthesizing antioxidant molecules to avoid excessive ROS, which otherwise would initiate cell death and introduce a constant prooxidative state in cancer cells $[20,137]$. Activation of T cells is escorted by increases in glucose uptake and mitochondrial activity fueled by glutaminolysis [138, 139]. Studies have shown that low ROS levels generated by mitochondria are pivotal for NFAT (nuclear factor of activated $\mathrm{T}$ cells) activation and IL-2 production by $\mathrm{T}$ cells $[140,141]$. By contradiction, ROS can selectively suppress the DNA-binding capacities of NF- $\kappa \mathrm{B}$ and NFAT, resulting in the downregulation of IL-2 transcription [142]. ROS being generated upon TCR engagement regulate ERK proliferative pathways and CD95/CD95L proapoptotic pathways, critical for normal $\mathrm{T}$ cell responses [143]. Hence, uncontrolled surplus ROS generation in the melanoma TME leads to nonfunctional T cells and failure to develop $\mathrm{T}_{\text {eff }}$ or $\mathrm{T}_{\mathrm{m}}$ responses. Henceforth, ROS levels must be buffered in a safe range for clonal expansion and differentiation of an activated $\mathrm{T}$ cell through metabolic reprogramming. This is a daunting task, as antioxidants would improve $\mathrm{T}$ cell activity while at the same time also fueling melanoma growth.

In contrast to normal fibroblasts, which are responsible for the turnover of extracellular matrix (ECM), ROSactivated cancer-associated fibroblasts (CAFs) can be found at the edge of tumors or infiltrating the tumor [144-146]. These cells are a potent source of ROS, adding to the already hostile micro milieu [147]. Another considerable role of CAFs is to enhance tumorigenesis by activating specific signaling pathways crucial for promoting tumor growth. For instance, this is done through AKT in epithelial cells and the secretion of soluble factors like CXCL12 [148]. The domination of CAFs within cancer tissues is correlated with poor prognosis, elevated infiltration of tumor-associated macrophages, epithelial to mesenchymal transition, and ROSdriven hypoxia [149]. Hypoxia created by desmoplasia, in turn, stimulates the production of mitochondrial ROS, which can influence CAF function [150]. CAFs expressing smooth-muscle $\alpha$-actin ( $\alpha$-SMA) are called myofibroblasts. The role of ROS in transition from fibroblasts to myofibroblasts is well reported, and this transition is driven by factors such as transforming growth factor betal (TGF- $\beta 1$ ) and stromal cell-derived factor 1 (SDF-1) in a ROS-dependent manner [151]. Moreover, chronic oxidative stress also leads to the differentiation of fibroblasts to myofibroblasts. These ROS effects can be reversed with prolonged exogenous anti- oxidants in fibroblasts isolated from mouse models of oxidative stress that lack prominent antioxidant transcription factors [152]. In addition, antioxidant enzymes such as GPX3 and thioredoxin reductase I upregulation within fibroblasts inhibit differentiation into myofibroblasts. The conclusion of these observations establishes that ROS can enhance specific fibroblast subtypes, including the predominant myofibroblast differentiation in human tumors [153]. ROS produced by fibroblast can also augment tumorigenesis [154]. Numerous studies focused on the role of $\mathrm{H}_{2} \mathrm{O}_{2}$ in TME and stroma [155]. The $\mathrm{H}_{2} \mathrm{O}_{2}$ is produced by tumor epithelial cells and can diffuse to adjacent cells, inducing a more protumorigenic environment. This effect can be abrogated with the addition of CAT [155].

ROS levels are the prominent factor in deciding its role as a signaling molecule or oxidative stress-causing agent, leading to activation of various defense mechanisms or cell death [156]. ROS can regulate autophagy through LC3associated autophagosomes or AMP-activated protein kinase (AMPK) and the regulation of gene transcription factor activity like NF- $\kappa \mathrm{B}$ inducing autophagy gene expression (BECLIN1/ATG6 or SQSTM1/p62) and unfolded protein response (UPR) during hypoxia [157]. Autophagy plays a complex role in the initiation of cancer [158]. Fibroblasts have $\mathrm{p} 21^{\text {Ras }}$-independent ROS generating enzymatic systems which set up extracellular $\mathrm{H}_{2} \mathrm{O}_{2}$ in response to TGF- $\beta 1$ [159]. In addition, an enzyme similar to 15-LOX in fibroblasts has been shown to procreate substantial amounts of $\mathrm{O}_{2}{ }^{-}$that developed without flavoenzyme activity [160]. These modifications have a crucial impact on the proteins' signaling and functional role, augment genome instability, prevent inflammation, and make cancer cells survive under hypoxia and starvation [15]. In addition, elevation in autophagy is associated with metastasis and poor prognosis in melanoma patients [161].

\section{ROS in Melanoma Therapy with Physical Modalities}

The pillars of oncology are surgery, chemotherapy, radiotherapy, and immunotherapy. Especially, the latter three involve the generation of ROS as a byproduct or as a targeted approach to eliminate melanoma. Besides, several physical modalities have emerged throughout the past three decades that come with therapeutic ROS production. A comprehensive review on all present and experimental therapeutic chemotherapeutic, biological, and immunological modalities for melanoma treatment is out of scope of this review. All these approaches are systemic treatments where local control of ROS production may be challenging. Instead, we here focus on local treatments of physical modalities reported to come with augmented ROS production (Figure 6).

4.1. Radiotherapy. Radiotherapy is one of the key therapeutic options in oncology. Radiotherapy produces radiationinduced ROS. For instance, $\mathrm{OH}$. is formed directly by the radiolysis of water molecules or indirectly by the formation of secondary ROS [162]. These molecules indiscriminately attack nearby molecules such as DNA and target membranes 


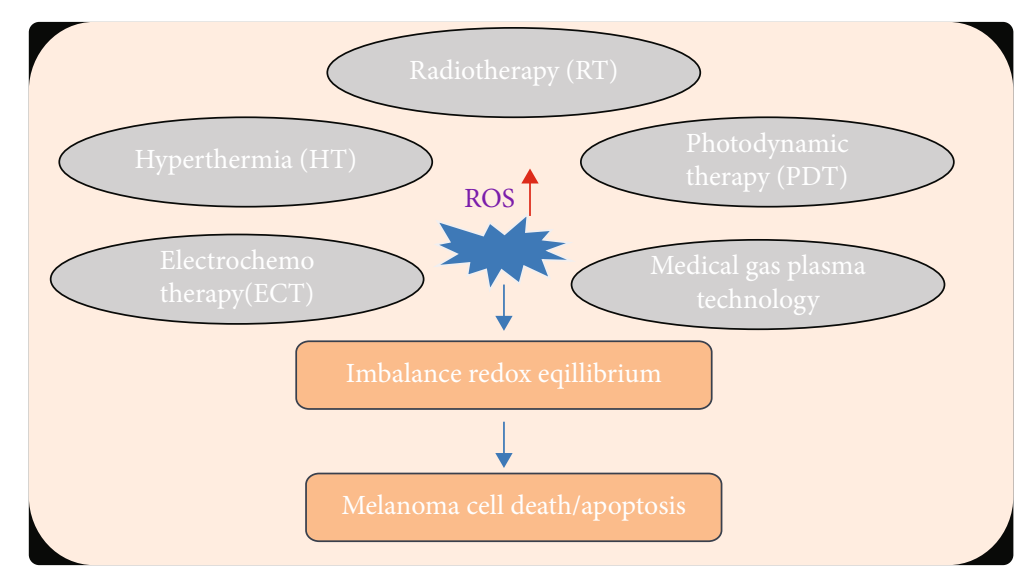

FIgURE 6: Physical therapy modalities exploiting supraphysiological ROS for melanoma treatment. Several treatments exploit ROS-based effects, including radiotherapy, photodynamic therapy, cryoablation, hyperthermia, and gas plasma technology. ROS induced by these therapies lead to an imbalance in redox equilibrium and subsequently promote melanoma cell death.

of cells and organelles, leading to cell cycle arrest and apoptosis [163]. ROS induced by radiation can induce cell death through necrosis, autophagy, mitotic cell death, and cell cycle arrest [163]. The mechanism varies by cell- and tissue-specific factors. ROS generated by radiation triggers DNA damage and apoptosis $[162,163]$. Radiotherapy may cause damage to normal tissues alongside tumor. Resistance or sensitivity of tumor cells to radiotherapy depends on cell cycle phase, endogenous antioxidant levels, oxygen availability, and gene expression. Many tumors divide slowly due to their long duration time in the S-phase/interphase of the cell cycle. Therefore, they get more time to repair the damaged DNA, which results in radiation resistance [164]. Several studies showed that mitotic cells with the lowest SH-AOs (SH-containing groups) are most radiosensitive than Sphase cells, which have the highest levels of these compounds $[164,165]$. Henceforth, synchronization of the cell cycle under these two sensitive cell cycle phases supports tumor eradication [166]. Moreover, rapidly dividing tumors are more prone to ROS-induced oxidative damage than slowly dividing tumors $[165,167]$. In addition, MAPK activation and VEGF release after radiation result in reduced tumor cell response, as shown by several experimental studies [168]. ROS-regulated MAPK determines whether tumor cells proliferate or undergo cell cycle arrest or apoptosis. Lastly, the DNA damage ability of ionizing radiation can be reduced by the antioxidant molecules inside the cells [165]. Several studies have shown that depletion of GSH and its synergistic effects with thioredoxin could increase the radiosensitivity of squamous cell carcinoma cell lines [169]. Intriguingly, depletion of ROS scavengers in cancer stem cells (CSCs) rapidly decreases their clonogenicity and consequence in radiosensitization [170].

The role of NRF2 in radioresistance is well described by recent studies [171, 172]. Aberration of NRF2 activation due to decreased KEAP1-NRF2 interaction and loss of mutations of KEAP1 leads to radiotherapy resistance [172]. In the presence of certain antioxidants, resistant tumor cells respond to radiation-induced killing mostly via ROS-mediated apoptosis $[162,165,168,172]$. However, there is limited evidence for definitive radiation therapy in melanoma, besides palliation [173]. However, retrospective and phase II studies have divulged that adjuvant radiotherapy can significantly improve the local-regional control rate in a specific clinical setting [174]. Adjuvant radiotherapy is offered to patients who are at high risk of recurrence [175]. Dose and fractionation schedules depend upon the melanoma site, even though the optimal radiation fractionation schedule remains controversial and convenient for patients with low survival expectations. ROS production is a well-recognized mechanism in radiotherapy $[176,177]$. This occurs during the tumor treatment and after that, as ROS are being released by stressed and dying cells in the TME due to uncoupled ETC and subsequent superoxide production. Accordingly, antioxidants were found to dampen the efficacy of radiotherapy in preclinical cancer models [178]. Moreover, hypoxic tumors were found to show enhanced radioresistant, and combination treatment with ROS-promoting therapies has been hypothesized to overcome this limitation [179].

4.2. Cryoablation. Cryoablation is an intrusive treatment that uses nitrogen or argon gas to create extreme cold to freeze and destroy tumors. The therapy induces tumor cell death by necrosis, hyperosmosis, and apoptosis [180]. Therefore, the treatment is not tightly entangled with the action of ROS [181], but since the therapy is an integral part of melanoma management, it is briefly outlined here nevertheless. The intracellular contents of cryoablation-damaged cells remain preserved for the immune system's recognition to initiate a tumor-specific immune response. Cryoablation slows down the rate of tumor spread and weakens tumor load by ablation of the primary site [182]. Cryoablation combined with distinct immunostimulants enhances the efficacy of cryoablation for the suppression of new tumor growth in metastatic mouse models $[183,184]$. This combination can overcome the limitations of immunotherapy. The combination of cryoablation with various immunostimulants (including TLR9 and CPG) has suppressed new tumor growth in metastatic mouse models $[184,185]$. In a recent study, cryoablation combined with a transarterial infusion 
of pembrolizumab has shown promising clinical activity in managing melanoma liver metastasis. However, the efficacy of the therapy needs to be confirmed with a controlled trial in the future [186]. ROS production can be anticipated with this destructive modality, but the therapeutic relevance for cryoablation-related ROS in melanoma remains limited as of now.

4.3. Electrochemotherapy. Electrochemotherapy (ECT) is a technique that involves the harmonious use of highintensity electric pulses to the tumor to increase the cytotoxicity of anticancer drugs, bleomycin and cisplatin, via electroporation [187]. The therapeutic efficacy of electroporation itself without drug application is negligible [188]. The cytotoxicity of drugs such as cisplatin and bleomycin increases by a factor of 100-1000 by electroporation of cell membranes [189]. ECT results demonstrate to be effective for treating cutaneous and subcutaneous malignant melanoma modules [190]. No major negative AEs were observed [191]. ROS production is a byproduct of the pulsed electric field treatment and plays a role in its efficacy [192] as it can be prevented by antioxidants $[193,194]$. ROS production and oxidative stress were also observed in electroporated melanoma cells in vitro [195]. Novel ECT approaches involve calcium electroporation with promising clinical results [196]. The treatment engages antitumor immunity to promote systemic attack of metastasis distant to the treatment side [197]. A case report showing such an abscopal effect in a melanoma patient has been published [198]. The calcium treatment locally elevates ROS that contributes to this effect $[199,200]$ and modulates the tumor vasculature [201]. Hence, this physical treatment modality might be a promising approach for treating therapyresistant melanoma metastasis, as well as releasing tumor antigen for immunotherapies. A study protocol for a randomized clinical trial in this regard for skin cancer treatment was recently published [202].

4.4. Hyperthermia. Hyperthermia is described as the use of exogenous heat sources that directly kill tumor cells or intensify the efficacy of other therapeutic means (e.g., radiotherapy, chemotherapy, and immunotherapies) against various cancer types. Mild hyperthermia as an adjuvant has shown improved antitumor immune response in preclinical and clinical data [203-205]. Hyperthermia generates heatshock proteins, induces the activation and migration o dendritic cells (DCs), increases the efficacy of tumor antigen presentation, and releases chemo attractants to tumor sites for leukocyte immigration and activation [206]. In vitro studies have shown that hyperthermia inhibits the mobility and proliferative ability of B16F10 cells in a temperaturedependent manner and regulates the TGF- $\beta 1$ protein expression in mouse malignant melanoma B16F10 cells both in vivo and in vitro [207]. In a metastatic mouse model, hyperthermia has significantly extended survival in an animal model. In addition, hyperthermia enhances the therapeutic effectiveness of drugs by activating caspase- 8 and caspase-9 to trigger apoptotic responses [208]. The imperative role of ROS in hyperthermia therapy has been thor- oughly described [209]. Mechanistically, hyperthermia elevates the levels of transition metal ions, which leads to enhanced production of $\mathrm{H}_{2} \mathrm{O}_{2}$ and $\mathrm{OH}^{\circ}$ by mediating mitochondrial damage. This can be controlled by the amount and duration of heat applied. In doing so, the heat shock also promotes autophagy and local apoptosis [210] while preserving the ability to mount antitumor immunity. Therefore, hyperthermia is well suited to be combined with, e.g., checkpoint therapy. The hyperthermic treatment will generate controlled melanoma cell destruction ROS-dependent and locally restricted without any debulking or therapeutic intent. The tumor antigens subsequently released may then augment antitumor immunity that, in combination with checkpoint therapy, will promote the systemic targeting of melanoma metastasis [211]. This ROS and stress-based heat therapy also show great promise in combination with targeted and nontargeted chemotherapy [208]. Clinical research on hyperthermia in melanoma therapy exists [212], but only a few centers work with techniques so far.

4.5. Medical Gas Plasma Technology. Along similar lines, gas plasma technology may be usefully combined with existing oncotherapies [213]. In contrast to hyperthermia, where heat and ROS are generated within the melanoma tissues at sufficient depths, gas plasma technology generates exogenous ROS applied topically to the treatment target [214]. Therefore, it might be well suited in the palliative setting for ulcerating melanoma lesions not covered by skin [215]. Gas plasma technology is unique in generating a plethora of ROS simultaneously with dozens of different agents [216]. The concentration of the ROS can be tuned by changing the ionization variables and the target exposure time [217], while the ambient air condition was found to have a lower impact [218]. As a mechanism of action, gas plasmaderived ROS modulate the expression of redox-regulating enzymes and pathways [219-221] and was found to show combinatorial effects with chemotherapy [222-224], radiotherapy [225-227], and antibody [228] and topical immunotherapy [229]. We have recently also reported for the first time apoptotic effects in patient-derived melanoma tissues [230] and that ROS-derived oxidative posttranslational protein modifications (oxPTMs) generated with gas plasma technology have immunogenic properties and protect from melanoma growth in vivo [231]. Such an approach would be entirely novel in upgrading antitumor vaccines [232] used, for instance, for autologous DC vaccination. Intriguingly, we were also the first to report an abscopal effect in a model of breast cancer where the tumor size of an untreated murine flank decreased in parallel to that of the treated flank, suggesting engagement of antitumor immunity using gas plasma-derived therapeutic ROS [233], as suggested before using human NK cell-mediated melanoma killing in vitro [234]. Gas plasma technology is safe and virtually free of side effects [235-237]. Several devices are marketed in Europe based on accreditation as medical device class IIa [238]. Clinical experience shows promising results in treating actinic keratosis [239-241] and locally advanced head and neck cancer in palliative patients [242-244], and more clinical research is heavily awaited. 


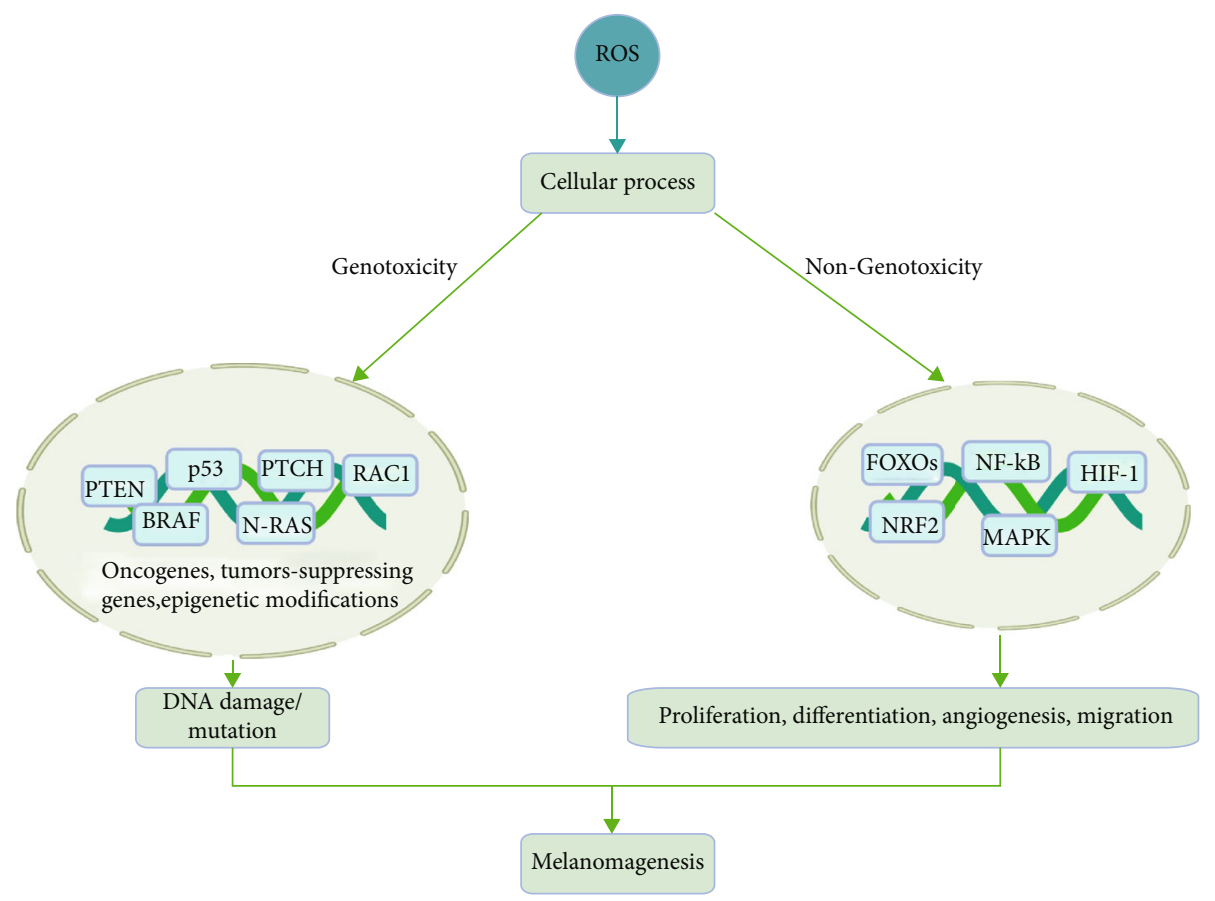

FIGURE 7: ROS role in melanomagenesis. High ROS levels activate protooncogenes, inactivate tumor suppressor genes, and cause genetic modifications. This leads to DNA damage and mutations and involves cellular signaling that blunts DNA repair and cell death and drives melanomagenesis. Conversely, signaling pathways less involved in DNA repair, such as MAPK, NF- $\kappa \mathrm{B}, \mathrm{PI} 3 \mathrm{~K} / \mathrm{AKT} / \mathrm{mTOR}$, and NRF2 spur melanoma cells' proliferation, angiogenesis, and metastasis. Together, these processes cause the occurrence of melanoma. Created with http://biorender.com.

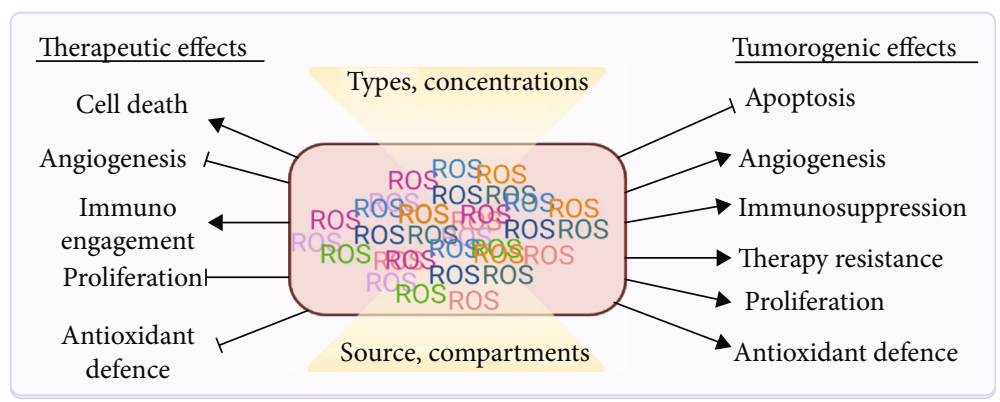

FIgURE 8: Pleitropic roles of ROS in melanoma. ROS have pleitropic roles in melanoma therapy and tumorigenesis depending on their source, concentration, location, and types. Created with http://biorender.com.

4.6. Photodynamic Therapy. Photodynamic therapy (PDT) has a long-standing application in the clinic already. This light-based and minimally invasive therapy is promising and effective in various types of cancers including nonmelanoma and melanoma skin cancer, for patients with stage III/IV cutaneous metastatic melanomas [245]. PDT is a minimally invasive procedure [246] that requires a photosensitizer (PS) molecule which, upon excitation by the specific wavelength of light, reacts with oxygen and causes oxidant species in target tissues, leading to increased ROS production, redox signaling, and cell death [247]. The advantage of PDT is its low systemic toxicity and its ability to destroy tumors selectively [246]. ROS, especially singlet oxygen, unleash irreversible damage to tumor cells and tumorassociated blood vessels, also activating antitumor immunity via inflammatory responses [248]. The limited penetration of light restricts the clinical use of PDT. For better efficacy of PDT in melanoma, overcoming protective mechanisms such as pigmentation and oxidative stress resistance is necessary to treat intracutaneous lesions [249]. The concepts and challenges of oxidative stress and PDT in skin cancer have been elegantly reported recently [250]. Clinically, PDT can be used along with other procedures, such as surgery, radiotherapy, or chemotherapy [251, 252]. Combined therapies have been studied to overcome melanoma resistance. The combination of PDT and chemotherapy (dacarbazine) was an efficient treatment to overcome the internal resistance in metastatic melanoma [253]. Most ongoing trials for cancer are using the photosensitizers that are approved for clinical use, mainly ALA (aminolevulinic acid) and photofrin (porfimer sodium) [254]. Combining PDT with immunoadjuvants to stimulate the antitumor immunity was more 
efficient and safer for treating melanoma than the monotherapies strategy [255], but still needs more clinical studies to elaborate efficacy and safety.

\section{Conclusion}

Following a review of ROS' divergent biological processes, some generalizations regarding the induction and function of ROS can be made. Importantly, ROS are generally induced by cell stress, starvation, hypoxia, and growth factor stimulation. Mild ROS induction promotes adaptation to ROS stress via HIF activation under hypoxia, inflammatory cytokine production in tissue damage, and differentiation in receptor-dependent stimulation, conjointly promoting cell survival (Figure 7). Although ROS have been recognized as important second messengers in cell biology, they have only recently gained attention concerning melanoma biology. At higher levels, ROS are detrimental, and several physical modalities directly or indirectly exploit such damaging functions for the treatment of skin cancer (Figure 8), including melanoma. As primary and metastatic melanoma provides high dynamic and plasticity in the TME, specifically targeting ROS is challenging as melanoma cells adapt to altered redox environments.

Even though the failure of dietary antioxidants in several clinical trials resulted in the emergence of alternative antimelanoma therapeutic approaches, there is still considerable controversy as to whether the use of either antioxidant supplementation or inhibition of ROS modulation is detrimental or beneficial for melanoma treatment. The effect of ROS is predominantly near the site of ROS production. Therefore, the use of inhibitors or antioxidants may prevent melanomagenesis. In addition to that, prooxidant melanoma therapy, through which scavenging of ROS is decreased or production of ROS is increased, or both, is a pioneering approach to exploit the higher levels of ROS in cancer cells to elicit cell death selectively. The eminent role of ROS modulation in antimelanoma therapies like ROS-inducing drugs and physical modalities, such as radiotherapy and photodynamic therapy, is well reported. It follows that combination therapies, e.g., checkpoint inhibition and ROS-generating therapies, might constitute novel avenues for targeting melanoma. While more preclinical and clinical research is excitingly awaited, the data known to date are encouraging that understanding, targeting, and utilizing ROS in melanoma treatment might be an effective adjuvant treatment in patient therapy in the future.
Abbreviations

$\begin{array}{ll}\text { CAFs: } & \text { Cancer-associated fibroblasts } \\ \text { CAT: } & \text { Catalase } \\ \text { ECM: } & \text { Extracellular matrix } \\ \text { ECT: } & \text { Electrochemotherapy } \\ \text { ETC: } & \text { Electron transport chain } \\ \text { GPX: } & \text { Glutathione peroxidase } \\ \text { GSH: } & \text { Glutathione } \\ \text { GSS: } & \text { Glutathione synthetase } \\ \text { GSSG: } & \text { Oxidized glutathione }\end{array}$

$\mathrm{H}_{2} \mathrm{O}_{2}$ : Hydrogen peroxide

HIF: Hypoxia-inducible factor

IL: Interleukin

KEAP1: Kelch-like ECH-associated protein 1

MMP: Matrix metalloproteinases

NADPH: Nicotinamide adenine dinucleotide phosphate

NF- $\kappa$ B: Nuclear factor kappa-light-chain-enhancer of activated B cells

NOS: $\quad$ Nitric oxide synthase

NOX: NADPH oxidase

NRF2: $\quad$ Nuclear factor erythroid 2-related factor 2

$\mathrm{O}_{2}{ }^{-}$: $\quad$ Superoxide ion

$\mathrm{OH} \cdot \quad$ Hydroxyl radical

PDT: $\quad$ Photodynamic therapy

PRDX: peroxiredoxins

ROS: $\quad$ Reactive oxygen species

SOD: $\quad$ Superoxide dismutase.

\section{Conflicts of Interest}

The authors declare no conflict of interest.

\section{Acknowledgments}

The work of SB is supported by the German Federal Ministry of Education and Research (BMBF, grant number 03Z22DN11), the European Social Fund ("ONKOTHERH," ESF/14-BM-A55-0006/18), and the Ministry of Education, Science and Culture of Mecklenburg-Vorpommern, Germany.

\section{References}

[1] J. R. Henderson, H. Swalwell, S. Boulton, P. Manning, C. J. McNeil, and M. A. Birch-Machin, "Direct, real-time monitoring of superoxide generation in isolated mitochondria," Free Radical Research, vol. 43, no. 9, pp. 796-802, 2009.

[2] H. Sies, C. Berndt, and D. P. Jones, “Oxidative stress," Annual Review of Biochemistry, vol. 86, no. 1, pp. 715-748, 2017.

[3] A. Schmidt and S. Bekeschus, "Redox for repair: cold physical plasmas and Nrf2 signaling promoting wound healing," Antioxidants, vol. 7, no. 10, p. 146, 2018.

[4] K. V. Donkena, C. Y. Young, and D. J. Tindall, "Oxidative stress and DNA methylation in prostate cancer," Obstetrics and Gynecology International, vol. 2010, Article ID 302051, 14 pages, 2010.

[5] T. Finkel, "Oxygen radicals and signaling," Current Opinion in Cell Biology, vol. 10, no. 2, pp. 248-253, 1998.

[6] T. Gao, B. T. Joyce, L. Liu et al., "DNA methylation of oxidative stress genes and cancer risk in the normative aging study," American Journal of Cancer Research, vol. 6, pp. 553-561, 2016.

[7] A. M. Gorman, "Neuronal cell death in neurodegenerative diseases: recurring themes around protein handling," Journal of Cellular and Molecular Medicine, vol. 12, no. 6a, pp. 22632280, 2008.

[8] D. Harman, "Aging: a theory based on free radical and radiation chemistry," Journal of Gerontology, vol. 11, no. 3, pp. 298-300, 1956. 
[9] S. G. Rhee, Y. S. Bae, S. R. Lee, and J. Kwon, "Hydrogen peroxide: a key messenger that modulates protein phosphorylation through cysteine oxidation," Science Signaling, vol. 2000, no. 53, 2000.

[10] H. Sies and D. P. Jones, "Reactive oxygen species (ROS) as pleiotropic physiological signalling agents," Nature Reviews Molecular Cell Biology, vol. 21, no. 7, pp. 363-383, 2020.

[11] C. Espinosa-Diez, V. Miguel, D. Mennerich et al., "Antioxidant responses and cellular adjustments to oxidative stress," Redox Biology, vol. 6, pp. 183-197, 2015.

[12] L. A. Sena and N. S. Chandel, "Physiological roles of mitochondrial reactive oxygen species," Molecular Cell, vol. 48, no. 2, pp. 158-167, 2012.

[13] N. Brandes, S. Schmitt, and U. Jakob, "Thiol-based redox switches in eukaryotic proteins," Antioxidants \& Redox Signaling, vol. 11, no. 5, pp. 997-1014, 2009.

[14] C. R. Rocha, G. S. Kajitani, A. Quinet, R. S. Fortunato, and C. F. Menck, "Nrf2 and glutathione are key resistance mediators to temozolomide in glioma and melanoma cells," Oncotarget, vol. 7, no. 30, pp. 48081-48092, 2016.

[15] K. Balamurugan, "HIF-1 at the crossroads of hypoxia, inflammation, and cancer," International Journal of Cancer, vol. 138, no. 5, pp. 1058-1066, 2016.

[16] N. S. Chandel, M. G. Vander Heiden, C. B. Thompson, and P. T. Schumacker, "Redox regulation of p53 during hypoxia," Oncogene, vol. 19, no. 34, pp. 3840-3848, 2000.

[17] A. Tramutola, S. Falcucci, U. Brocco et al., "Protein oxidative damage in uv-related skin cancer and dysplastic lesions contributes to neoplastic promotion and progression," Cancers, vol. 12, no. 1, p. 110, 2020.

[18] J. Blumberg and G. Block, "The alpha-tocopherol, betacarotene cancer prevention study in finland," Nutrition Reviews, vol. 52, no. 7, pp. 242-245, 1994.

[19] E. A. Klein, I. M. Thompson Jr., C. M. Tangen et al., "Vitamin e and the risk of prostate cancer," JAMA, vol. 306, no. 14, pp. 1549-1556, 2011.

[20] C. Gorrini, I. S. Harris, and T. W. Mak, "Modulation of oxidative stress as an anticancer strategy," Nature Reviews Drug Discovery, vol. 12, no. 12, pp. 931-947, 2013.

[21] N. S. Chandel and D. A. Tuveson, "The promise and perils of antioxidants for cancer patients," The New England Journal of Medicine, vol. 371, no. 2, pp. 177-178, 2014.

[22] S. A. Del Prete, L. H. Maurer, J. O'Donnell, R. J. Forcier, and P. LeMarbre, "Combination chemotherapy with cisplatin, carmustine, dacarbazine, and tamoxifen in metastatic melanoma," Cancer Treatment Reports, vol. 68, pp. 1403-1405, 1984.

[23] V. Monge-Fuentes, L. A. Muehlmann, J. P. Longo et al., "Photodynamic therapy mediated by acai oil (Euterpe oleracea Martius) in nanoemulsion: A potential treatment for melanoma," Journal of Photochemistry and Photobiology B: Biology, vol. 166, pp. 301-310, 2017.

[24] F. V. Almeida, S. M. Douglass, M. E. Fane, and A. T. Weeraratna, "Bad company: microenvironmentally mediated resistance to targeted therapy in melanoma," Pigment Cell \& Melanoma Research, vol. 32, no. 2, pp. 237-247, 2019.

[25] D. G. Franchina, C. Dostert, and D. Brenner, "Reactive oxygen species: involvement in t cell signaling and metabolism," Trends in Immunology, vol. 39, no. 6, pp. 489-502, 2018.

[26] K. Keyer and J. A. Imlay, "Superoxide accelerates DNA damage by elevating free-iron levels," Proceedings of the National
Academy of Sciences of the United States of America, vol. 93, no. 24, pp. 13635-13640, 1996.

[27] K. Bedard and K. H. Krause, "The nox family of rosgenerating nadph oxidases: physiology and pathophysiology," Physiological Reviews, vol. 87, no. 1, pp. 245-313, 2007.

[28] H. Sies, "Hydrogen peroxide as a central redox signaling molecule in physiological oxidative stress: oxidative eustress," Redox Biology, vol. 11, pp. 613-619, 2017.

[29] K. S. Echtay, M. P. Murphy, R. A. Smith, D. A. Talbot, and M. D. Brand, "Superoxide Activates Mitochondrial Uncoupling Protein 2 from the Matrix Side," Journal of Biological Chemistry, vol. 277, no. 49, pp. 47129-47135, 2002.

[30] M. Sattler, T. Winkler, S. Verma et al., "Hematopoietic growth factors signal through the formation of reactive oxygen species," Blood, vol. 93, no. 9, pp. 2928-2935, 1999.

[31] B. P. Tu and J. S. Weissman, "The FAD- and $\mathrm{O}_{2}$-Dependent Reaction Cycle of Ero1-Mediated Oxidative Protein Folding in the Endoplasmic Reticulum," Molecular Cell, vol. 10, no. 5, pp. 983-994, 2002.

[32] C. C. Winterbourn, "Toxicity of iron and hydrogen peroxide: the fenton reaction," Toxicology Letters, vol. 82-83, pp. 969974, 1995.

[33] A. Ayala, M. F. Munoz, and S. Arguelles, "Lipid peroxidation: production, metabolism, and signaling mechanisms of malondialdehyde and 4-hydroxy-2-nonenal," Oxidative Medicine and Cellular Longevity, vol. 2014, Article ID 360438, 31 pages, 2014.

[34] B. R. Stockwell, J. P. Friedmann Angeli, H. Bayir et al., "Ferroptosis: a regulated cell death nexus linking metabolism, redox biology, and disease," Cell, vol. 171, no. 2, pp. 273285, 2017.

[35] K. L. Fong, P. B. McCay, J. L. Poyer, H. P. Misra, and B. B. Keele, "Evidence for superoxide-dependent reduction of $\mathrm{fe}^{3+}$ and its role in enzyme-generated hydroxyl radical formation," Chemico-Biological Interactions, vol. 15, no. 1, pp. 7789, 1976.

[36] H. R. Stennicke, Q. L. Deveraux, E. W. Humke, J. C. Reed, V. M. Dixit, and G. S. Salvesen, "Caspase-9 Can Be Activated without Proteolytic Processing," Journal of Biological Chemistry, vol. 274, no. 13, pp. 8359-8362, 1999.

[37] S. H. Kaufmann and W. C. Earnshaw, "Induction of apoptosis by cancer chemotherapy," Experimental Cell Research, vol. 256, no. 1, pp. 42-49, 2000.

[38] V. E. Kagan, V. A. Tyurin, J. Jiang et al., "Cytochrome $c$ acts as a cardiolipin oxygenase required for release of proapoptotic factors," Nature Chemical Biology, vol. 1, no. 4, pp. 223232, 2005.

[39] G. Paradies, G. Petrosillo, M. Pistolese, N. Di Venosa, A. Federici, and F. M. Ruggiero, "Decrease in mitochondrial complex i activity in ischemic/reperfused rat Heart," Circulation Research, vol. 94, no. 1, pp. 53-59, 2004.

[40] M. D. Brand, "The sites and topology of mitochondrial superoxide production," Experimental Gerontology, vol. 45, no. 78, pp. 466-472, 2010.

[41] F. L. Muller, Y. Liu, and H. Van Remmen, "Complex III Releases Superoxide to Both Sides of the Inner Mitochondrial Membrane," Journal of Biological Chemistry, vol. 279, no. 47, pp. 49064-49073, 2004.

[42] J. D. Lambeth, G. Cheng, R. S. Arnold, and W. A. Edens, "Novel homologs of gp91 phox," Trends in Biochemical Sciences, vol. 25, no. 10, pp. 459-461, 2000. 
[43] S. S. Brar, T. P. Kennedy, A. R. Whorton et al., "Reactive oxygen species from $\operatorname{nad}(\mathrm{p}) \mathrm{h}$ :quinone oxidoreductase constitutively activate NF- $\kappa \mathrm{B}$ in malignant melanoma cells," American Journal of Physiology-Cell Physiology, vol. 280, no. 3, pp. C659-C676, 2001.

[44] F. Liu, A. M. Gomez Garcia, and F. L. Meyskens Jr., "Nadph oxidase 1 overexpression enhances invasion via matrix metalloproteinase-2 and epithelial-mesenchymal transition in melanoma cells," Journal of Investigative Dermatology, vol. 132, no. 8, pp. 2033-2041, 2012.

[45] M. G. Espey, D. D. Thomas, K. M. Miranda, and D. A. Wink, "Focusing of nitric oxide mediated nitrosation and oxidative nitrosylation as a consequence of reaction with superoxide," Proceedings of the National Academy of Sciences of the United States of America, vol. 99, no. 17, pp. 11127-11132, 2002.

[46] S. C. Albrecht, A. G. Barata, J. Grosshans, A. A. Teleman, and T. P. Dick, "In vivo mapping of hydrogen peroxide and oxidized glutathione reveals chemical and regional specificity of redox homeostasis," Cell Metabolism, vol. 14, no. 6, pp. 819-829, 2011.

[47] I. Hirono, "Mechanism of natural and acquired resistance to methyl-bis-(beta-chlorethyl)-amine n-oxide in ascites tumors," Gan, vol. 52, pp. 39-48, 1961.

[48] S. C. Lu, "Regulation of glutathione synthesis," Molecular Aspects of Medicine, vol. 30, no. 1-2, pp. 42-59, 2009.

[49] D. W. Nebert and V. Vasiliou, "Analysis of the glutathione stransferase (gst) gene family," Human Genomics, vol. 1, no. 6, pp. 460-464, 2004.

[50] A. Holmgren and M. Bjornstedt, "[21] Thioredoxin and thioredoxin reductase," Methods in Enzymology, vol. 252, pp. 199-208, 1995.

[51] S. C. Lu, "Glutathione synthesis," Biochimica et Biophysica Acta (BBA) - General Subjects, vol. 1830, no. 5, pp. 31433153, 2013.

[52] C. C. Winterbourn and M. B. Hampton, "Thiol chemistry and specificity in redox signaling," Free Radical Biology \& Medicine, vol. 45, no. 5, pp. 549-561, 2008.

[53] J. Lu and A. Holmgren, "The thioredoxin antioxidant system," Free Radical Biology \& Medicine, vol. 66, pp. 75-87, 2014.

[54] S. Gidanian, M. Mentelle, F. L. Meyskens Jr., and P. J. Farmer, "Melanosomal damage in normal human melanocytes induced by uvb and metal uptake-a basis for the prooxidant state of melanoma," Photochemistry and Photobiology, vol. 84, no. 3, pp. 556-564, 2008.

[55] R. Sarangarajan and S. P. Apte, "The polymerization of melanin: a poorly understood phenomenon with egregious biological implications," Melanoma Research, vol. 16, no. 1, pp. 3-10, 2006.

[56] L. C. Godoy, C. T. Anderson, R. Chowdhury, L. J. Trudel, and G. N. Wogan, "Endogenously produced nitric oxide mitigates sensitivity of melanoma cells to cisplatin," Proceedings of the National Academy of Sciences of the United States of America, vol. 109, no. 50, pp. 20373-20378, 2012.

[57] F. H. Melo, F. Molognoni, A. S. Morais et al., "Endothelial nitric oxide synthase uncoupling as a key mediator of melanocyte malignant transformation associated with sustained stress conditions," Free Radical Biology \& Medicine, vol. 50, no. 10, pp. 1263-1273, 2011.

[58] M. T. Landi, J. Bauer, R. M. Pfeiffer et al., "MC1RGermline variants confer risk forBRAF-Mutant melanoma," Science, vol. 313 , no. 5786, pp. 521-522, 2006.
[59] N. C. Jenkins, T. Liu, P. Cassidy et al., "The p $16^{\mathrm{INK} 4 \mathrm{~A}}$ tumor suppressor regulates cellular oxidative stress," Oncogene, vol. 30, no. 3, pp. 265-274, 2011.

[60] B. Govindarajan, J. E. Sligh, B. J. Vincent et al., "Overexpression of akt converts radial growth melanoma to vertical growth melanoma," Journal of Clinical Investigation, vol. 117, no. 3, pp. 719-729, 2007.

[61] K. Itoh, N. Wakabayashi, Y. Katoh et al., "Keap1 represses nuclear activation of antioxidant responsive elements by Nrf2 through binding to the amino-terminal Neh2 domain," Genes \& Development, vol. 13, no. 1, pp. 76-86, 1999.

[62] J. D. Hayes and M. McMahon, "NRF2 and KEAP1 mutations: permanent activation of an adaptive response in cancer," Trends in Biochemical Sciences, vol. 34, no. 4, pp. 176-188, 2009.

[63] R. Wang, J. An, F. Ji, H. Jiao, H. Sun, and D. Zhou, "Hypermethylation of the _Keap1_gene in human lung cancer cell lines and lung cancer tissues," Biochemical and Biophysical Research Communications, vol. 373, no. 1, pp. 151-154, 2008.

[64] H. Zhu, Z. Jia, M. A. Trush, and Y. R. Li, "Nrf2 deficiency promotes melanoma growth and lung metastasis," Reactive Oxygen Species, vol. 2, pp. 308-314, 2016.

[65] E. V. Knatko, M. Higgins, J. W. Fahey, and A. T. DinkovaKostova, "Loss of Nrf2 abrogates the protective effect of Keap1 downregulation in a preclinical model of cutaneous squamous cell carcinoma," Scientific Reports, vol. 6, no. 1, article 25804, 2016.

[66] C. Wiel, K. Le Gal, M. X. Ibrahim et al., "Bach1 stabilization by antioxidants stimulates lung cancer metastasis," Cell, vol. 178, no. 2, pp. 330-345.e22, 2019.

[67] C. S. Sander, H. Chang, F. Hamm, P. Elsner, and J. J. Thiele, "Role of oxidative stress and the antioxidant network in cutaneous carcinogenesis," International Journal of Dermatology, vol. 43, no. 5, pp. 326-335, 2004.

[68] D. T. Lincoln, E. M. Ali Emadi, K. F. Tonissen, and F. M. Clarke, "The thioredoxin-thioredoxin reductase system: over-expression in human cancer," Anticancer Research, vol. 23, pp. 2425-2433, 2003.

[69] A. Baldi, D. Lombardi, P. Russo et al., "Ferritin contributes to melanoma progression by modulating cell growth and sensitivity to oxidative stress," Clinical Cancer Research, vol. 11, no. 9, pp. 3175-3183, 2005.

[70] J. M. Stahl, A. Sharma, M. Cheung et al., "Deregulated Akt3 activity promotes development of malignant melanoma," Cancer Research, vol. 64, no. 19, pp. 7002-7010, 2004.

[71] J. Liu, K. G. Suresh Kumar, D. Yu et al., "Oncogenic BRAF regulates $\beta$-Trcp expression and NF- $\kappa \mathrm{B}$ activity in human melanoma cells," Oncogene, vol. 26, no. 13, pp. 1954-1958, 2007.

[72] K. S. Smalley, "A pivotal role for erk in the oncogenic behaviour of malignant melanoma?," International Journal of Cancer, vol. 104, no. 5, pp. 527-532, 2003.

[73] M. Verhaegen, J. A. Bauer, C. Martín de la Vega et al., "A novel bh3 mimetic reveals a mitogen-activated protein kinase-dependent mechanism of melanoma cell death controlled by p53 and reactive oxygen species," Cancer Research, vol. 66, no. 23, pp. 11348-11359, 2006.

[74] G. Gloire, S. Legrand-Poels, and J. Piette, "NF- $\kappa$ B activation by reactive oxygen species: Fifteen years later," Biochemical Pharmacology, vol. 72, no. 11, pp. 1493-1505, 2006.

[75] M. Karin, "Nuclear factor $-\kappa \mathrm{B}$ in cancer development and progression," Nature, vol. 441, no. 7092, pp. 431-436, 2006. 
[76] Y. Ueda and A. Richmond, "NF-kappab activation in melanoma," Pigment Cell Research, vol. 19, no. 2, pp. 112-124, 2006.

[77] A. S. Payne and L. A. Cornelius, "The role of chemokines in melanoma tumor growth and metastasis," Journal of Investigative Dermatology, vol. 118, no. 6, pp. 915-922, 2002.

[78] S. Xanthoudakis, G. Miao, F. Wang, Y. C. E. Pan, and T. Curran, "Redox activation of Fos-Jun DNA binding activity is mediated by a DNA repair enzyme," The EMBO Journal, vol. 11, no. 9, pp. 3323-3335, 1992.

[79] T. Smeal, B. Binetruy, D. A. Mercola, M. Birrer, and M. Karin, "Oncogenic and transcriptional cooperation with Ha-Ras requires phosphorylation of c-Jun on serines 63 and 73," Nature, vol. 354, no. 6353, pp. 494-496, 1991.

[80] J. Westermarck, J. Lohi, J. Keskioja, and V. M. Kahari, “Okadaic acid-elicited transcriptional activation of collagenase gene-expression in HT-1080 fibrosarcoma cells is mediated by JunB," Cell Growth and Differentiation, vol. 5, pp. 12051213, 1994.

[81] M. H. Kim, H. S. Cho, M. Jung et al., "Extracellular signalregulated kinase and AP-1 pathways are involved in reactive oxygen species-induced urokinase plasminogen activator receptor expression in human gastric cancer cells," International Journal of Oncology, vol. 26, pp. 1669-1674, 2005.

[82] N. J. de Wit, G. N. van Muijen, and D. J. Ruiter, "Immunohistochemistry in melanocytic proliferative lesions," Histopathology, vol. 44, no. 6, pp. 517-541, 2004.

[83] A. Vartanian and A. Y. Baryshnikov, "Crosstalk between apoptosis and antioxidants in melanoma vasculogenic mimicry," Advances in Experimental Medicine and Biology, vol. 601, pp. 145-153, 2007.

[84] R. Clarijs, D. J. Ruiter, and R. M. W. de Waal, "Pathophysiological implications of stroma pattern formation in uveal melanoma," Journal of Cellular Physiology, vol. 194, no. 3, pp. 267-271, 2003.

[85] M. J. Hendrix, E. A. Seftor, A. R. Hess, and R. E. Seftor, "Vasculogenic mimicry and tumour-cell plasticity: lessons from melanoma," Nature Reviews Cancer, vol. 3, no. 6, pp. 411421, 2003.

[86] L. M. Postovit, E. A. Seftor, R. E. Seftor, and M. J. Hendrix, "Influence of the microenvironment on melanoma cell fate determination and Phenotype: Figure 1," Cancer Research, vol. 66, no. 16, pp. 7833-7836, 2006.

[87] M. R. Abid, K. C. Spokes, S. C. Shih, and W. C. Aird, "Nadph oxidase activity selectively modulates vascular endothelial growth factor signaling pathways," Journal of Biological Chemistry, vol. 282, no. 48, pp. 35373-35385, 2007.

[88] B. Bedogni, S. M. Welford, D. S. Cassarino, B. J. Nickoloff, A. J. Giaccia, and M. B. Powell, "The hypoxic microenvironment of the skin contributes to akt-mediated melanocyte transformation," Cancer Cell, vol. 8, no. 6, pp. 443454, 2005.

[89] A. L. Harris, "Hypoxia - a key regulatory factor in tumour growth," Nature Reviews Cancer, vol. 2, no. 1, pp. 38-47, 2002.

[90] S. Moniz, J. Biddlestone, and S. Rocha, "Grow(2): the HIF system, energy homeostasis and the cell cycle," Histology and Histopathology, vol. 29, pp. 589-600, 2014.

[91] J. Fandrey, T. A. Gorr, and M. Gassmann, "Regulating cellular oxygen sensing by hydroxylation," Cardiovascular Research, vol. 71, no. 4, pp. 642-651, 2006.
[92] D. A. Kirschmann, E. A. Seftor, S. F. Fong et al., "A molecular role for lysyl oxidase in breast cancer invasion," Cancer Research, vol. 62, pp. 4478-4483, 2002.

[93] M. Callapina, J. Zhou, T. Schmid, R. Kohl, and B. Brune, "NO restores HIF- $1 \alpha$ hydroxylation during hypoxia: Role of reactive oxygen species," Free Radical Biology \& Medicine, vol. 39, no. 7, pp. 925-936, 2005.

[94] Z. Li, D. Wang, E. M. Messing, and G. Wu, "VHL proteininteracting deubiquitinating enzyme 2 deubiquitinates and stabilizes HIF-1 $\alpha$," EMBO Reports, vol. 6, no. 4, pp. 373378, 2005.

[95] G. L. Wang and G. L. Semenza, "Desferrioxamine induces erythropoietin gene expression and hypoxia-inducible factor 1 DNA-binding activity: implications for models of hypoxia signal transduction," Blood, vol. 82, no. 12, pp. 3610-3615, 1993.

[96] Y. Yuan, G. Hilliard, T. Ferguson, and D. E. Millhorn, "Cobalt Inhibits the Interaction between Hypoxia-inducible Factor- $\alpha$ and von Hippel-Lindau Protein by Direct Binding to Hypoxia-inducible Factor- $\alpha$," Journal of Biological Chemistry, vol. 278, no. 18, pp. 15911-15916, 2003.

[97] K. Salnikow, S. P. Donald, R. K. Bruick, A. Zhitkovich, J. M. Phang, and K. S. Kasprzak, "Depletion of Intracellular Ascorbate by the Carcinogenic Metals Nickel and Cobalt Results in the Induction of Hypoxic Stress," Journal of Biological Chemistry, vol. 279, no. 39, pp. 40337-40344, 2004.

[98] N. Ferrara, "Vascular endothelial growth factor," Arteriosclerosis, Thrombosis, and Vascular Biology, vol. 29, no. 6, pp. 789-791, 2009.

[99] J. A. Forsythe, B. H. Jiang, N. V. Iyer et al., “Activation of vascular endothelial growth factor gene transcription by hypoxia-inducible factor 1," Molecular and Cellular Biology, vol. 16, no. 9, pp. 4604-4613, 1996.

[100] N. S. Chandel, W. C. Trzyna, D. S. McClintock, and P. T. Schumacker, "Role of oxidants in NF- $\kappa$ B activation and TNF- $\alpha$ gene transcription induced by hypoxia and endotoxin," The Journal of Immunology, vol. 165, no. 2, pp. 1013-1021, 2000.

[101] S. Kuphal, S. Wallner, and A. K. Bosserhoff, "Impact of LIF (leukemia inhibitory factor) expression in malignant melanoma," Experimental and Molecular Pathology, vol. 95, no. 2, pp. 156-165, 2013.

[102] J. P. Dutcher, "Mammalian target of rapamycin inhibition," Clinical Cancer Research, vol. 10, no. 18, pp. 6382S-6387S, 2004.

[103] O. Aprelikova, S. Pandolfi, S. Tackett et al., "Melanoma antigen-11 inhibits the hypoxia-inducible factor prolyl hydroxylase 2 and activates hypoxic response," Cancer Research, vol. 69, no. 2, pp. 616-624, 2009.

[104] S. Kuphal, A. Winklmeier, C. Warnecke, and A. K. Bosserhoff, "Constitutive HIF-1 activity in malignant melanoma," European Journal of Cancer, vol. 46, no. 6, pp. 1159-1169, 2010.

[105] Y. Chudnovsky, P. A. Khavari, and A. E. Adams, "Melanoma genetics and the development of rational therapeutics," Journal of Clinical Investigation, vol. 115, no. 4, pp. 813-824, 2005.

[106] R. M. MacKie, "Long-term health risk to the skin of ultraviolet radiation," Progress in Biophysics and Molecular Biology, vol. 92, no. 1, pp. 92-96, 2006. 
[107] J. A. Curtin, J. Fridlyand, T. Kageshita et al., "Distinct sets of genetic alterations in melanoma," The New England Journal of Medicine, vol. 353, no. 20, pp. 2135-2147, 2005.

[108] F. L. Meyskens Jr., P. J. Farmer, and H. Anton-Culver, "Etiologic pathogenesis of melanoma: Fig. 1," Clinical Cancer Research, vol. 10, no. 8, pp. 2581-2583, 2004.

[109] A. Slominski, M. A. Zmijewski, and J. Pawelek, "L-tyrosine and l-dihydroxyphenylalanine as hormone-like regulators of melanocyte functions," Pigment Cell \& Melanoma Research, vol. 25, no. 1, pp. 14-27, 2012.

[110] S. Pavel, F. van Nieuwpoort, H. van der Meulen et al., "Disturbed melanin synthesis and chronic oxidative stress in dysplastic naevi," European Journal of Cancer, vol. 40, no. 9, pp. 1423-1430, 2004.

[111] J. M. McCord, "Iron, free radicals, and oxidative injury," Seminars in Hematology, vol. 35, pp. 5-12, 1998.

[112] F. Liu-Smith, R. Dellinger, and F. L. Meyskens Jr., "Updates of reactive oxygen species in melanoma etiology and progression," Archives of Biochemistry and Biophysics, vol. 563, pp. 51-55, 2014.

[113] A. T. Slominski and J. A. Carlson, "Melanoma resistance: a bright future for academicians and a challenge for patient advocates," Mayo Clinic Proceedings, vol. 89, no. 4, pp. 429433, 2014.

[114] Y. Kamenisch, I. Ivanova, K. Drexler, and M. Berneburg, "UVA, metabolism and melanoma: UVA makes melanoma hungry for metastasis," Experimental Dermatology, vol. 27, no. 9, pp. 941-949, 2018.

[115] L. R. Arslanbaeva and M. M. Santoro, "Adaptive redox homeostasis in cutaneous melanoma," Redox Biology, vol. 37, article 101753, 2020.

[116] M. Hosseini, Z. Kasraian, and H. R. Rezvani, "Energy metabolism in skin cancers: a therapeutic perspective," Biochimica et Biophysica Acta (BBA) - Bioenergetics, vol. 1858, no. 8, pp. 712-722, 2017.

[117] P. R. Kumar, J. A. Moore, K. M. Bowles, S. A. Rushworth, and M. D. Moncrieff, "Mitochondrial oxidative phosphorylation in cutaneous melanoma," British Journal of Cancer, vol. 124, no. 1, pp. 115-123, 2021.

[118] L. C. van Kempen, G. N. van Muijen, and D. J. Ruiter, "Stromal responses in human primary melanoma of the skin," Frontiers in Bioscience, vol. 10, no. 1-3, pp. 2922-2931, 2005.

[119] J. B. Wyckoff, J. G. Jones, J. S. Condeelis, and J. E. Segall, “A critical step in metastasis: in vivo analysis of intravasation at the primary tumor," Cancer Research, vol. 60, pp. 25042511, 2000.

[120] T. Ota, M. Maeda, M. Tanino, and M. Tatsuka, "Functional suppression of integrin beta 4-mediated adhesion caused by in vivo sequential selection for cancer cell intravasation," Anticancer Research, vol. 21, pp. 205-211, 2001.

[121] J. Raffel, A. K. Bhattacharyya, A. Gallegos et al., "Increased expression of thioredoxin-1 in human colorectal cancer is associated with decreased patient survival," Journal of Laboratory and Clinical Medicine, vol. 142, no. 1, pp. 46-51, 2003.

[122] G. C. Cheng, P. C. Schulze, R. T. Lee, J. Sylvan, B. R. Zetter, and H. Huang, "Oxidative stress and thioredoxin-interacting protein promote intravasation of melanoma cells," Experimental Cell Research, vol. 300, no. 2, pp. 297-307, 2004.

[123] E. Piskounova, M. Agathocleous, M. M. Murphy et al., "Oxidative stress inhibits distant metastasis by human melanoma cells," Nature, vol. 527, no. 7577, pp. 186-191, 2015.
[124] K. Le Gal, M. X. Ibrahim, C. Wiel et al., "Antioxidants can increase melanoma metastasis in mice," Science Translational Medicine, vol. 7, 2015.

[125] R. A. Cairns, I. S. Harris, and T. W. Mak, "Regulation of cancer cell metabolism," Nature Reviews Cancer, vol. 11, no. 2, pp. 85-95, 2011.

[126] A. Glasauer and N. S. Chandel, "Targeting antioxidants for cancer therapy," Biochemical Pharmacology, vol. 92, no. 1, pp. 90-101, 2014.

[127] P. Allavena, C. Garlanda, M. G. Borrello, A. Sica, and A. Mantovani, "Pathways connecting inflammation and cancer," Current Opinion in Genetics \& Development, vol. 18, no. 1, pp. 3-10, 2008.

[128] L. M. Coussens and Z. Werb, "Inflammation and cancer," Nature, vol. 420, no. 6917, pp. 860-867, 2002.

[129] M. Pieniazek, R. Matkowski, and P. Donizy, "Macrophages in skin melanoma-the key element in melanomagenesis (Review)," Oncology Letters, vol. 15, pp. 5399-5404, 2018.

[130] C. Ceci, M. G. Atzori, P. M. Lacal, and G. Graziani, “Targeting tumor-associated macrophages to increase the efficacy of immune checkpoint inhibitors: a glimpse into novel therapeutic approaches for metastatic melanoma," Cancers, vol. 12, no. 11, p. 3401, 2020.

[131] H. Maeda and T. Akaike, "Nitric oxide and oxygen radicals in infection, inflammation, and cancer," Biochemistry, vol. 63, pp. 854-865, 1998.

[132] L. C. van Kempen, K. E. de Visser, and L. M. Coussens, "Inflammation, proteases and cancer," European Journal of Cancer, vol. 42, no. 6, pp. 728-734, 2006.

[133] I. Bohme and A. Bosserhoff, "Extracellular acidosis triggers a senescence-like phenotype in human melanoma cells," Pigment Cell \& Melanoma Research, vol. 33, no. 1, pp. 41-51, 2020.

[134] A. Indini, F. Grossi, M. Mandala, D. Taverna, and V. Audrito, "Metabolic interplay between the immune system and melanoma cells: therapeutic implications," Biomedicines, vol. 9, no. 6 , p. $607,2021$.

[135] B. A. Olenchock, J. C. Rathmell, and M. G. Vander Heiden, "Biochemical underpinnings of immune cell metabolic phenotypes," Immunity, vol. 46, no. 5, pp. 703-713, 2017.

[136] M. D. Buck, R. T. Sowell, S. M. Kaech, and E. L. Pearce, "Metabolic instruction of immunity," Cell, vol. 169, no. 4, pp. 570586, 2017.

[137] D. Brenner and T. W. Mak, "Mitochondrial cell death effectors," Current Opinion in Cell Biology, vol. 21, no. 6, pp. 871-877, 2009.

[138] S. R. Jacobs, C. E. Herman, N. J. Maciver et al., "Glucose uptake is limiting in $\mathrm{t}$ cell activation and requires CD28mediated akt-dependent and independent pathways," The Journal of Immunology, vol. 180, no. 7, pp. 4476-4486, 2008.

[139] E. L. Carr, A. Kelman, G. S. Wu et al., "Glutamine uptake and metabolism are coordinately regulated by erk/mapk during $\mathrm{t}$ lymphocyte activation," The Journal of Immunology, vol. 185, no. 2, pp. 1037-1044, 2010.

[140] L. A. Sena, S. Li, A. Jairaman et al., "Mitochondria are required for antigen-specific $t$ cell activation through reactive oxygen species signaling," Immunity, vol. 38, no. 2, pp. 225236, 2013.

[141] A. Quintana, C. Schwindling, A. S. Wenning et al., "T cell activation requires mitochondrial translocation to the immunological synapse," Proceedings of the National Academy of 
Sciences of the United States of America, vol. 104, no. 36, pp. 14418-14423, 2007.

[142] E. Flescher, J. A. Ledbetter, G. L. Schieven et al., "Longitudinal exposure of human t lymphocytes to weak oxidative stress suppresses transmembrane and nuclear signal transduction," The Journal of Immunology, vol. 153, pp. 4880-4889, 1994.

[143] S. Devadas, L. Zaritskaya, S. G. Rhee, L. Oberley, and M. S. Williams, "Discrete generation of superoxide and hydrogen peroxide by t cell receptor Stimulation," Journal of Experimental Medicine, vol. 195, no. 1, pp. 59-70, 2002.

[144] K. M. Holmstrom and T. Finkel, "Cellular mechanisms and physiological consequences of redox-dependent signalling," Nature Reviews Molecular Cell Biology, vol. 15, no. 6, pp. 411-421, 2014.

[145] D. Hanahan and L. M. Coussens, "Accessories to the crime: functions of cells recruited to the tumor microenvironment," Cancer Cell, vol. 21, no. 3, pp. 309-322, 2012.

[146] J. A. Joyce and J. W. Pollard, "Microenvironmental regulation of metastasis," Nature Reviews Cancer, vol. 9, no. 4, pp. 239252, 2009.

[147] J. S. Chan, M. J. Tan, M. K. Sng et al., "Cancer-associated fibroblasts enact field cancerization by promoting extratumoral oxidative stress," Cell Death \& Disease, vol. 8, article e2562, 2018.

[148] C. Kuperwasser, T. Chavarria, M. Wu et al., "From The Cover: Reconstruction of functionally normal and malignant human breast tissues in mice," Proceedings of the National Academy of Sciences of the United States of America, vol. 101, no. 14, pp. 4966-4971, 2004.

[149] P. Gascard and T. D. Tlsty, "Carcinoma-associated fibroblasts: orchestrating the composition of malignancy," Genes \& Development, vol. 30, no. 9, pp. 1002-1019, 2016.

[150] V. P. Chauhan, Y. Boucher, C. R. Ferrone et al., "Compression of pancreatic tumor blood vessels by hyaluronan is caused by solid stress and not interstitial fluid pressure," Cancer Cell, vol. 26, no. 1, pp. 14-15, 2014.

[151] Y. Kojima, A. Acar, E. N. Eaton et al., “Autocrine TGF- and stromal cell-derived factor-1 (SDF-1) signaling drives the evolution of tumor-promoting mammary stromal myofibroblasts," Proceedings of the National Academy of Sciences of the United States of America, vol. 107, no. 46, pp. 20009-20014, 2010.

[152] A. Toullec, D. Gerald, G. Despouy et al., "Oxidative stress promotes myofibroblast differentiation and tumour spreading," EMBO Molecular Medicine, vol. 2, no. 6, pp. 211-230, 2010.

[153] E. Artaud-Macari, D. Goven, S. Brayer et al., "Nuclear factor erythroid 2-related factor 2 nuclear translocation induces myofibroblastic dedifferentiation in idiopathic pulmonary fibrosis," Antioxidants \& Redox Signaling, vol. 18, no. 1, pp. 66-79, 2013.

[154] A. Costa, A. Scholer-Dahirel, and F. Mechta-Grigoriou, "The role of reactive oxygen species and metabolism on cancer cells and their microenvironment," Seminars in Cancer Biology, vol. 25, pp. 23-32, 2014.

[155] U. E. Martinez-Outschoorn, Z. Lin, C. Trimmer et al., "Cancer cells metabolically "fertilize" the tumor microenvironment with hydrogen peroxide, driving the warburg effect," Cell Cycle, vol. 10, no. 15, pp. 2504-2520, 2011.

[156] A. L. Levonen, B. G. Hill, E. Kansanen, J. Zhang, and V. M. Darley-Usmar, "Redox regulation of antioxidants, autoph- agy, and the response to stress: implications for electrophile therapeutics," Free Radical Biology \& Medicine, vol. 71, pp. 196-207, 2014.

[157] S. Arico, A. Petiot, C. Bauvy et al., "The Tumor Suppressor PTEN Positively Regulates Macroautophagy by Inhibiting the Phosphatidylinositol 3-Kinase/Protein Kinase B Pathway," Journal of Biological Chemistry, vol. 276, no. 38, pp. 35243-35246, 2001.

[158] S. Demirsoy, S. Martin, H. Maes, and P. Agostinis, "Adapt, recycle, and move on: proteostasis and trafficking mechanisms in melanoma," Frontiers in Oncology, vol. 6, p. 240, 2016.

[159] R. M. Liu and L. P. Desai, "Reciprocal regulation of TGF- $\beta$ and reactive oxygen species: A perverse cycle for fibrosis," Redox Biology, vol. 6, pp. 565-577, 2015.

[160] K. Richter and T. Kietzmann, "Reactive oxygen species and fibrosis: further evidence of a significant liaison," Cell and Tissue Research, vol. 365, no. 3, pp. 591-605, 2016.

[161] M. Ren, C. Y. Wei, L. Wang, X. Y. Deng, N. H. Lu, and J. Y. $\mathrm{Gu}$, "Integration of individual prediction index based on autophagy-related genes and clinical phenomes in melanoma patients," Clinical and Translational Medicine, vol. 10, no. 4, article e132, 2020.

[162] C. Borek, "Antioxidants and radiation therapy," The Journal of Nutrition, vol. 134, no. 11, pp. 3207S-3209S, 2004.

[163] G. Loo, "Redox-sensitive mechanisms of phytochemicalmediated inhibition of cancer cell proliferation ${ }^{1}$ (review)," The Journal of Nutritional Biochemistry, vol. 14, no. 2, pp. 64-73, 2003.

[164] A. Affolter, M. Drigotas, K. Fruth et al., "Increased radioresistance via G12S K-RAS by compensatory upregulation of MAPK and PI3K pathways in epithelial cancer," Head \& Neck, vol. 35, no. 2, pp. 220-228, 2013.

[165] K. N. Prasad, W. C. Cole, B. Kumar, and K. Che Prasad, "Pros and cons of antioxidant use during radiation therapy," Cancer Treatment Reviews, vol. 28, no. 2, pp. 79-91, 2002.

[166] S. U. Mertens-Talcott and S. S. Percival, "Ellagic acid and quercetin interact synergistically with resveratrol in the induction of apoptosis and cause transient cell cycle arrest in human leukemia cells," Cancer Letters, vol. 218, no. 2, pp. 141-151, 2005.

[167] W. K. Sinclair, "Cysteamine: Differential x-ray protective effect on chinese hamster cells during the cell cycle," Science, vol. 159, no. 3813, pp. 442-444, 1968.

[168] M. Drigotas, A. Affolter, W. J. Mann, and J. Brieger, "Reactive oxygen species activation of mapk pathway results in VEGF upregulation as an undesired irradiation response," Journal of Oral Pathology \& Medicine, vol. 42, no. 8, pp. 612-619, 2013.

[169] J. H. Cho, H. J. Lee, H. J. Ko et al., “The tlr7 agonist imiquimod induces anti-cancer effects via autophagic cell death and enhances anti-tumoral and systemic immunity during radiotherapy for melanoma," Oncotarget, vol. 8, no. 15, pp. 24932-24948, 2017.

[170] M. Diehn, R. W. Cho, N. A. Lobo et al., "Association of reactive oxygen species levels and radioresistance in cancer stem cells," Nature, vol. 458, no. 7239, pp. 780-783, 2009.

[171] H. Wang, S. Bouzakoura, S. de Mey et al., "Auranofin radiosensitizes tumor cells through targeting thioredoxin reductase and resulting overproduction of reactive oxygen species," Oncotarget, vol. 8, no. 22, pp. 35728-35742, 2017. 
[172] S. Zhou, W. Ye, Q. Shao, M. Zhang, and J. Liang, "Nrf2 is a potential therapeutic target in radioresistance in human cancer," Critical Reviews in Oncology/Hematology, vol. 88, no. 3, pp. 706-715, 2013.

[173] A. Mahadevan, V. L. Patel, and N. Dagoglu, "Radiation therapy in the management of malignant melanoma," Oncology, vol. 29, pp. 743-751, 2015.

[174] J. French, C. McGahan, G. Duncan, S. Lengoc, J. Soo, and J. Cannon, "How gender, age, and geography influence the utilization of radiation therapy in the management of malignant melanoma," International Journal of Radiation Oncology • Biology • Physics, vol. 66, no. 4, pp. 1056-1063, 2006.

[175] E. Fenig, E. Eidelevich, E. Njuguna et al., "Role of radiation therapy in the management of cutaneous malignant melanoma," American Journal of Clinical Oncology, vol. 22, no. 2, pp. 184-186, 1999.

[176] Q. Xie, G. Lan, Y. Zhou et al., "Strategy to enhance the anticancer efficacy of $\mathrm{X}$-ray radiotherapy in melanoma cells by platinum complexes, the role of ros-mediated signaling pathways," Cancer Letters, vol. 354, no. 1, pp. 58-67, 2014.

[177] H. H. W. Chen and M. T. Kuo, "Improving radiotherapy in cancer treatment: promises and challenges," Oncotarget, vol. 8, no. 37, pp. 62742-62758, 2017.

[178] D. F. Meng, L. L. Guo, L. X. Peng et al., “Antioxidants suppress radiation-induced apoptosis via inhibiting mapk pathway in nasopharyngeal carcinoma cells," Biochemical and Biophysical Research Communications, vol. 527, no. 3, pp. 770-777, 2020.

[179] H. Wang, H. Jiang, M. Van De Gucht, and M. De Ridder, "Hypoxic radioresistance: can ROS be the key to overcome it?," Cancers, vol. 11, no. 1, p. 112, 2019.

[180] B. M. Aarts, E. G. Klompenhouwer, S. L. Rice et al., "Cryoablation and immunotherapy: an overview of evidence on its synergy," Insights Imaging, vol. 10, no. 1, p. 53, 2019.

[181] R. L. Manthe, S. P. Foy, N. Krishnamurthy, B. Sharma, and V. Labhasetwar, "Tumor ablation and nanotechnology," Molecular Pharmaceutics, vol. 7, no. 6, pp. 1880-1898, 2010.

[182] J. J. Joosten, G. N. P. Muijen, T. Wobbes, and T. J. Ruers, "In Vivo Destruction of Tumor Tissue by Cryoablation Can Induce Inhibition of Secondary Tumor Growth: An Experimental Study," Cryobiology, vol. 42, no. 1, pp. 49-58, 2001.

[183] M. H. den Brok, R. P. Sutmuller, S. Nierkens et al., "Efficient loading of dendritic cells following cryo and radiofrequency ablation in combination with immune modulation induces anti-tumour immunity," British Journal of Cancer, vol. 95, no. 7, pp. 896-905, 2006.

[184] C. Kudo-Saito, T. Fuwa, and Y. Kawakami, "Targeting ALCAM in the cryo-treated tumour microenvironment successfully induces systemic anti-tumour immunity," European Journal of Cancer, vol. 62, pp. 54-61, 2016.

[185] S. Nierkens, M. H. den Brok, R. P. Sutmuller et al., "In vivoColocalization of antigen and cpg within dendritic cells is associated with the efficacy of cancer immunotherapy," Cancer Research, vol. 68, no. 13, pp. 5390-5396, 2008.

[186] L. Shen, H. Qi, S. Chen et al., "Cryoablation combined with transarterial infusion of pembrolizumab (catap) for liver metastases of melanoma: an ambispective, proof-of-concept cohort study," Cancer Immunology, Immunotherapy, vol. 69, no. 9, pp. 1713-1724, 2020.

[187] M. Fiorentzis, H. Kalirai, P. Katopodis, B. Seitz, A. Viestenz, and S. E. Coupland, "Electrochemotherapy with bleomycin and cisplatin enhances cytotoxicity in primary and metastatic uveal melanoma cell lines in vitro," Neoplasma, vol. 65, no. 2, pp. 210-215, 2018.

[188] C. M. Wolff, A. Steuer, I. Stoffels et al., "Combination of cold plasma and pulsed electric fields - A rationale for cancer patients in palliative care," Clinical Plasma Medicine, vol. 16, article 100096, 2019.

[189] M. A. O'Brien, D. G. Power, A. J. Clover, B. Bird, D. M. Soden, and P. F. Forde, "Local tumour ablative therapies: opportunities for maximising immune engagement and activation," Biochimica et Biophysica Acta (BBA) - Reviews on Cancer, vol. 2014, pp. 510-523, 2014.

[190] N. Mozzillo, C. Caraco, S. Mori et al., "Use of neoadjuvant electrochemotherapy to treat a large metastatic lesion of the cheek in a patient with melanoma," Journal of Translational Medicine, vol. 10, no. 1, p. 131, 2012.

[191] G. Sersa, B. Stabuc, M. Cemazar, D. Miklavcic, and Z. Rudolf, "Electrochemotherapy with cisplatin: clinical experience in malignant melanoma patients," Clinical Cancer Research, vol. 6, pp. 863-867, 2000.

[192] R. M. Brock, N. Beitel-White, R. V. Davalos, and I. C. Allen, "Starting a fire without flame: the induction of cell death and inflammation in electroporation-based tumor ablation strategies," Frontiers in Oncology, vol. 10, p. 1235, 2020.

[193] G. Sersa, J. Teissie, M. Cemazar et al., "Electrochemotherapy of tumors as in situ vaccination boosted by immunogene electrotransfer," Cancer Immunology, Immunotherapy, vol. 64, no. 10, pp. 1315-1327, 2015.

[194] C. M. Wolff, J. F. Kolb, K. D. Weltmann, T. von Woedtke, and S. Bekeschus, "Combination treatment with cold physical plasma and pulsed electric fields augments ros production and cytotoxicity in lymphoma," Cancers, vol. 12, no. 4, p. 845, 2020.

[195] W. Szlasa, A. Kielbik, A. Szewczyk et al., "Oxidative effects during irreversible electroporation of melanoma cellsin vitro study," Molecules, vol. 26, 2021.

[196] D. Agoston, E. Baltas, H. Ocsai et al., "Evaluation of calcium electroporation for the treatment of cutaneous metastases: a double blinded randomised controlled phase II trial," Cancers, vol. 12, no. 1, p. 179, 2020.

[197] H. Falk, P. F. Forde, M. L. Bay et al., "Calcium electroporation induces tumor eradication, long-lasting immunity and cytokine responses in the CT26 colon cancer mouse model," Oncoimmunology, vol. 6, no. 5, article e1301332, 2017.

[198] H. Falk, S. Lambaa, H. H. Johannesen, G. Wooler, A. Venzo, and J. Gehl, "Electrochemotherapy and calcium electroporation inducing a systemic immune response with local and distant remission of tumors in a patient with malignant melanoma - a case report," Acta Oncologica, vol. 56, no. 8, pp. 1126-1131, 2017.

[199] S. K. Frandsen and J. Gehl, “A review on differences in effects on normal and malignant cells and tissues to electroporationbased therapies: a focus on calcium electroporation," Technology in Cancer Research \& Treatment, vol. 17, 2018.

[200] K. L. Hoejholt, T. Muzic, S. D. Jensen et al., "Calcium electroporation and electrochemotherapy for cancer treatment: Importance of cell membrane composition investigated by lipidomics, calorimetry and_in vitro_efficacy," Scientific Reports, vol. 9, no. 1, p. 4758, 2019.

[201] B. Staresinic, T. Jesenko, U. Kamensek et al., "Effect of calcium electroporation on tumour vasculature," Scientific Reports, vol. 8, no. 1, p. 9412, 2018. 
[202] M. Vissing, J. Ploen, M. Pervan et al., "Study protocol designed to investigate tumour response to calcium electroporation in cancers affecting the skin: a non-randomised phase ii clinical trial," BMJ Open, vol. 11, no. 6, article e046779, 2021.

[203] J. J. Skitzki, E. A. Repasky, and S. S. Evans, "Hyperthermia as an immunotherapy strategy for cancer," Current Opinion in Investigational Drugs, vol. 10, pp. 550-558, 2009.

[204] M. Nishikawa, S. Takemoto, and Y. Takakura, "Heat shock protein derivatives for delivery of antigens to antigen presenting cells," International Journal of Pharmaceutics, vol. 354, no. 1-2, pp. 23-27, 2008.

[205] T. Takeda, K. Fukunaga, K. Miyazawa et al., "Hyperthermic immuno-cellular therapy-basic and clinical study," Gan To Kagaku Ryoho, vol. 35, pp. 2244-2246, 2008.

[206] Y. Tamura, N. Tsuboi, N. Sato, and K. Kikuchi, "70 kDa heat shock cognate protein is a transformation-associated antigen and a possible target for the host's anti-tumor immunity," Journal of Immunology, vol. 151, pp. 5516-5524, 1993.

[207] H. Jin, X. Xie, B. Hu et al., "Hyperthermia inhibits the proliferation and invasive ability of mouse malignant melanoma through TGF- $\beta 1$," Oncology Reports, vol. 29, no. 2, pp. 725734, 2013.

[208] T. Mantso, S. Vasileiadis, I. Anestopoulos et al., "Hyperthermia induces therapeutic effectiveness and potentiates adjuvant therapy with non-targeted and targeted drugs in an _in vitro_ model of human malignant melanoma," Scientific Reports, vol. 8, no. 1, article 10724, 2018.

[209] I. Belhadj Slimen, T. Najar, A. Ghram, H. Dabbebi, M. Ben Mrad, and M. Abdrabbah, "Reactive oxygen species, heat stress and oxidative-induced mitochondrial damage. A review," International Journal of Hyperthermia, vol. 30, no. 7, pp. 513-523, 2014.

[210] S. Kassis, M. Grondin, and D. A. Averill-Bates, "Heat shock increases levels of reactive oxygen species, autophagy and apoptosis," Biochimica et Biophysica Acta (BBA) - Molecular Cell Research, vol. 1868, no. 3, article 118924, 2021.

[211] M. D. Hurwitz, "Hyperthermia and immunotherapy: clinical opportunities," International Journal of Hyperthermia, vol. 36, no. sup1, pp. 4-9, 2019.

[212] K. Engin, L. Tupchong, D. Phil et al., "Hyperthermia and radiation in advanced malignant melanoma," International Journal of Radiation Oncology • Biology • Physics, vol. 25, no. 1, pp. 87-94, 1993.

[213] H. R. Metelmann, C. Seebauer, R. Rutkowski, M. Schuster, S. Bekeschus, and P. Metelmann, "Treating cancer with cold physical plasma: on the way to evidence-based medicine," Contributions to Plasma Physics, vol. 58, no. 5, pp. 415-419, 2018.

[214] A. Privat-Maldonado, A. Schmidt, A. Lin et al., "ROS from physical plasmas: redox chemistry for biomedical therapy," Oxidative Medicine and Cellular Longevity, vol. 2019, Article ID 9062098, 29 pages, 2019.

[215] G. Pasqual-Melo, R. K. Gandhirajan, I. Stoffels, and S. Bekeschus, "Targeting malignant melanoma with physical plasmas," Clinical Plasma Medicine, vol. 10, pp. 1-8, 2018.

[216] K. Wende, T. von Woedtke, K. D. Weltmann, and S. Bekeschus, "Chemistry and biochemistry of cold physical plasma derived reactive species in liquids," Biological Chemistry, vol. 400, pp. 19-38, 2019.

[217] S. Bekeschus, A. Schmidt, F. Niessner, T. Gerling, K. D. Weltmann, and K. Wende, "Basic research in plasma medicine - a throughput approach from liquids to cells," Journal of Visualized Experiments, no. 129, article e56331, 2017.

[218] S. Hasse, T. Meder, E. Freund, T. von Woedtke, and S. Bekeschus, "Plasma treatment limits human melanoma spheroid growth and metastasis independent of the ambient gas composition," Cancers, vol. 12, no. 9, p. 2570, 2020.

[219] S. Bekeschus, S. Eisenmann, S. K. Sagwal et al., "xCT (SLC7A11) expression confers intrinsic resistance to physical plasma treatment in tumor cells," Redox Biology, vol. 30, article 101423, 2020.

[220] R. K. Gandhirajan, D. Meyer, S. K. Sagwal, K. D. Weltmann, T. von Woedtke, and S. Bekeschus, "The amino acid metabolism is essential for evading physical plasma-induced tumour cell death," British Journal of Cancer, vol. 124, no. 11, pp. 1854-1863, 2021.

[221] S. Bekeschus, R. Clemen, L. Haralambiev et al., "The plasmainduced leukemia cell death is dictated by the ROS chemistry and the HO-1/CXCL8 axis," IEEE Transactions on Radiation and Plasma Medical Sciences, vol. 5, no. 3, pp. 398-411, 2021.

[222] L. Brulle, M. Vandamme, D. Ries et al., "Effects of a non thermal plasma treatment alone or in combination with gemcitabine in a MIA PaCa2-luc orthotopic pancreatic carcinoma model," PLoS One, vol. 7, no. 12, article e52653, 2012.

[223] S. K. Sagwal, G. Pasqual-Melo, Y. Bodnar, R. K. Gandhirajan, and S. Bekeschus, "Combination of chemotherapy and physical plasma elicits melanoma cell death via upregulation of SLC22A16," Cell Death \& Disease, vol. 9, no. 12, p. 1179, 2018.

[224] P. Shaw, N. Kumar, A. Privat-Maldonado, E. Smits, and A. Bogaerts, "Cold atmospheric plasma increases temozolomide sensitivity of three-dimensional glioblastoma spheroids via oxidative stress-mediated DNA damage," Cancers, vol. 13, no. 8 , p. 1780, 2021.

[225] J. Lafontaine, J. S. Boisvert, A. Glory, S. Coulombe, and $\mathrm{P}$. Wong, "Synergy between non-thermal plasma with radiation therapy and olaparib in a panel of breast cancer cell lines," Cancers, vol. 12, no. 2, p. 348, 2020.

[226] G. Pasqual-Melo, S. K. Sagwal, E. Freund et al., "Combination of gas plasma and radiotherapy has immunostimulatory potential and additive toxicity in murine melanoma cells in vitro," International Journal of Molecular Sciences, vol. 21, no. 4, p. 1379, 2020.

[227] J.-S. Boisvert, J. Lafontaine, A. Glory, S. Coulombe, and P. Wong, "Comparison of three radio-frequency discharge modes on the treatment of breast cancer Cellsin vitro," IEEE Transactions on Radiation and Plasma Medical Sciences, vol. 4, no. 5, pp. 644-654, 2020.

[228] G. Chen, Z. Chen, D. Wen et al., "Transdermal cold atmospheric plasma-mediated immune checkpoint blockade therapy," Proceedings of the National Academy of Sciences of the United States of America, vol. 117, no. 7, pp. 3687-3692, 2020.

[229] S. Bekeschus, R. Clemen, F. Niessner, S. K. Sagwal, E. Freund, and A. Schmidt, "Medical gas plasma jet technology targets murine melanoma in an immunogenic fashion," Advanced Science, vol. 7, no. 10, article 1903438, 2020.

[230] S. Bekeschus, J. Moritz, I. Helfrich et al., "Ex vivo exposure of human melanoma tissue to cold physical plasma elicits apoptosis and modulates inflammation," Applied Sciences, vol. 10, no. 6, p. 1971, 2020.

[231] R. Clemen, E. Freund, D. Mrochen et al., "Gas plasma technology augments ovalbumin immunogenicity and OT-II $t$ 
cell activation conferring tumor protection in mice," Advanced Science, vol. 8, no. 10, article 2003395, 2021.

[232] R. Clemen and S. Bekeschus, "Ros cocktails as an adjuvant for personalized antitumor vaccination?," Vaccines, vol. 9, no. 5, p. 527, 2021.

[233] H. Mahdikia, F. Saadati, E. Freund et al., "Gas plasma irradiation of breast cancers promotes immunogenicity, tumor reduction, and an abscopal effect in vivo," Oncoimmunology, vol. 10, article 1859731, 2021.

[234] R. Clemen, P. Heirman, A. Lin, A. Bogaerts, and S. Bekeschus, "Physical plasma-treated skin cancer cells amplify tumor cytotoxicity of human natural killer (NK) cells," Cancers, vol. 12, no. 12, p. 3575, 2020.

[235] S. Bekeschus, A. Schmidt, A. Kramer et al., "High throughput image cytometry micronucleus assay to investigate the presence or absence of mutagenic effects of cold physical plasma," Environmental and Molecular Mutagenesis, vol. 59, no. 4, pp. 268-277, 2018.

[236] L. Miebach, E. Freund, S. Horn et al., "Tumor cytotoxicity and immunogenicity of a novel V-jet neon plasma source compared to the kINPen," Scientific Reports, vol. 11, no. 1, p. 136, 2021.

[237] R. Rutkowski, G. Daeschlein, T. von Woedtke, R. Smeets, M. Gosau, and H. R. Metelmann, "Long-term risk assessment for medical application of cold atmospheric pressure plasma," Diagnostics, vol. 10, no. 4, p. 210, 2020.

[238] S. Bekeschus, T. von Woedtke, S. Emmert, and A. Schmidt, "Medical gas plasma-stimulated wound healing: evidence and mechanisms," Redox Biology, vol. 46, p. 102116, 2021.

[239] M. Arisi, S. Soglia, E. Guasco Pisani et al., "Cold atmospheric plasma (CAP) for the treatment of actinic keratosis and skin field cancerization: clinical and high-frequency ultrasound evaluation," Dermatology and Therapy, vol. 11, no. 3, pp. 855-866, 2021.

[240] G. Daeschlein, A. Arnold, S. Lutze et al., "Treatment of recalcitrant actinic keratosis (AK) of the scalp by cold atmospheric plasma," Cogent Medicine, vol. 4, no. 1, article 1412903, 2017.

[241] P. C. Friedman, V. Miller, G. Fridman, A. Lin, and A. Fridman, "Successful treatment of actinic keratoses using nonthermal atmospheric pressure plasma: a case series," Journal of the American Academy of Dermatology, vol. 76, no. 2, pp. 349-350, 2017.

[242] H.-R. Metelmann, D. S. Nedrelow, C. Seebauer et al., "Head and neck cancer treatment and physical plasma," Clinical Plasma Medicine, vol. 3, no. 1, pp. 17-23, 2015.

[243] H.-R. Metelmann, C. Seebauer, V. Miller et al., "Clinical experience with cold plasma in the treatment of locally advanced head and neck cancer," Clinical Plasma Medicine, vol. 9, pp. 6-13, 2018.

[244] M. Schuster, C. Seebauer, R. Rutkowski et al., "Visible tumor surface response to physical plasma and apoptotic cell kill in head and neck cancer," Journal of the American Academy of Dermatology, vol. 44, no. 9, pp. 1445-1452, 2016.

[245] E. Buytaert, M. Dewaele, and P. Agostinis, "Molecular effectors of multiple cell death pathways initiated by photodynamic therapy," Journal of Cranio-Maxillofacial Surgery, vol. 2007, pp. 86-107, 2007.

[246] T. J. Dougherty, C. J. Gomer, B. W. Henderson et al., "Photodynamic therapy," Journal of the National Cancer Institute, vol. 90, no. 12, pp. 889-905, 1998.
[247] P. Mroz, A. Yaroslavsky, G. B. Kharkwal, and M. R. Hamblin, "Cell death pathways in photodynamic therapy of cancer," Cancers, vol. 3, no. 2, pp. 2516-2539, 2011.

[248] R. Falk-Mahapatra and S. O. Gollnick, "Photodynamic therapy and immunity: an update," Photochemistry and Photobiology, vol. 96, no. 3, pp. 550-559, 2020.

[249] Y. Y. Huang, D. Vecchio, P. Avci, R. Yin, M. Garcia-Diaz, and M. R. Hamblin, "Melanoma resistance to photodynamic therapy: new insights," Biological Chemistry, vol. 394, no. 2, pp. 239-250, 2013.

[250] A. Allegra, G. Pioggia, A. Tonacci, C. Musolino, and S. Gangemi, "Oxidative stress and photodynamic therapy of skin cancers: mechanisms, challenges and promising developments," Antioxidants, vol. 9, no. 5, p. 448, 2020.

[251] J. Xu, J. Q. Gao, and Q. C. Wei, "Combination of photodynamic therapy with radiotherapy for cancer treatment," Journal of Nanomaterials, vol. 2016, Article ID 8507924, 7 pages, 2016.

[252] M. Wachowska, A. Muchowicz, and J. Golab, "Targeting epigenetic processes in photodynamic therapy-induced anticancer immunity," Frontiers in Oncology, vol. 5, p. 176, 2015.

[253] F. N. Biteghe and L. M. Davids, "A combination of photodynamic therapy and chemotherapy displays a differential cytotoxic effect on human metastatic melanoma cells," Journal of Photochemistry and Photobiology B: Biology, vol. 166, pp. 1827, 2017.

[254] S. M. Gondivkar, A. R. Gadbail, M. G. Choudhary, P. R. Vedpathak, and M. S. Likhitkar, "Photodynamic treatment outcomes of potentially-malignant lesions and malignancies of the head and neck region: a systematic review," Journal of Investigative and Clinical Dentistry, vol. 9, no. 1, article e12270, 2018

[255] H. S. Hwang, H. Shin, J. Han, and K. Na, "Combination of photodynamic therapy (PDT) and anti-tumor immunity in cancer therapy," Journal of Pharmaceutical Investigation, vol. 48, no. 2, pp. 143-151, 2018. 